ARTICLE

Received 1 Jul 2015 | Accepted 23 Oct 2015 | Published 8 Dec 2015

DOl: $10.1038 /$ ncomms9997 OPEN

\title{
EPPS rescues hippocampus-dependent cognitive deficits in APP/PS1 mice by disaggregation of amyloid- $\beta$ oligomers and plaques
}

Hye Yun Kim ${ }^{1,2,3}$, Hyunjin Vincent Kim ${ }^{1,2}$, Seonmi Jo ${ }^{4}$, C. Justin Lee ${ }^{4}$, Seon Young Choi ${ }^{1}$, Dong Jin Kim ${ }^{1}$ \& YoungSoo $\mathrm{Kim}^{1,2}$

\begin{abstract}
Alzheimer's disease (AD) is characterized by the transition of amyloid- $\beta(A \beta)$ monomers into toxic oligomers and plaques. Given that $A \beta$ abnormality typically precedes the development of clinical symptoms, an agent capable of disaggregating existing $A \beta$ aggregates may be advantageous. Here we report that a small molecule, 4-(2-hydroxyethyl)-1piperazinepropanesulphonic acid (EPPS), binds to $A \beta$ aggregates and converts them into monomers. The oral administration of EPPS substantially reduces hippocampus-dependent behavioural deficits, brain $A \beta$ oligomer and plaque deposits, glial $\gamma$-aminobutyric acid (GABA) release and brain inflammation in an A $\beta$-overexpressing, APP/PS1 transgenic mouse model when initiated after the development of severe AD-like phenotypes. The ability of EPPS to rescue $A \beta$ aggregation and behavioural deficits provides strong support for the view that the accumulation of $A \beta$ is an important mechanism underlying $A D$.
\end{abstract}

\footnotetext{
${ }^{1}$ Center for Neuro-Medicine, Brain Science Institute, Korea Institute of Science and Technology (KIST), Hwarangno 14-gil 5, Seongbuk-gu, Seoul 136-791, Republic of Korea. ${ }^{2}$ Biological Chemistry Program, Korea University of Science and Technology (UST), 217 Gajungro Yuseong-gu, Daegeon 305-806, Republic of Korea. ${ }^{3}$ Research Institute, GoshenBiotech Inc., 78, Sure-ro 640beon-gil, Wabu-eup, Namyangju-si, Gyeonggi-do 472-905, Republic of Korea. ${ }^{4}$ Center for Neuroscience, Brain Science Institute, Korea Institute of Science and Technology (KIST), Hwarangno 14-gil 5, Seongbuk-gu, Seoul 136-791, Republic of Korea. Correspondence and requests for materials should be addressed to D.J.K. (email: djk2991@kist.re.kr) or to Y.K. (email: yskim@bio.kist.re.kr).
} 
$\mathrm{D}$ uring Alzheimer's disease (AD) pathogenesis, amyloid- $\beta$ (A $\beta)$ monomers aberrantly aggregate into toxic oligomers, fibrils and eventually plaques. The concentration of misfolded $A \beta$ species highly correlates with the severity of neurotoxicity and inflammation that leads to neurodegeneration in $\mathrm{AD}^{1-3}$. Accordingly, substantial efforts have been devoted to reducing $A \beta$ levels, including methods to prevent the production and aggregation of $A \beta^{4-7}$. Although these approaches effectively prevent the de novo formation of $A \beta$ aggregates, existing $A \beta$ oligomers and plaques will still remain in the patient's brain ${ }^{8-10}$. Thus, the desirable effects of $A \beta$ inhibitors may be expected when administered before a patient develops toxic $A \beta$ deposits ${ }^{5-7}$. However, in $\mathrm{AD}$ patients with mild-to-moderate symptoms, antiamyloidogenic agents have not yielded expected outcomes, which may be due to the incomplete removal of pre-existing $A \beta$ aggregates ${ }^{11}$. As $A \beta$ typically begins to aggregate long before the onset of $\mathrm{AD}$ symptoms, interventions specifically aimed at disaggregating existing plaques and oligomers may constitute a useful approach to $\mathrm{AD}$ treatment, perhaps in parallel with agents aimed at inhibiting aggregate formation ${ }^{8-12}$.

\section{Results}

EPPS reduces A $\beta$-aggregate-induced memory deficits in mice. Previously, we reported a series of small ionic molecules that could accelerate the formation of $A \beta$ aggregates in vitro. Unexpectedly, in addition to the compounds facilitating $A \beta$ aggregation, we identified six small molecules that inhibited the formation of $A \beta$ oligomers and fibrils ${ }^{13}$. In the current study, we tested whether these molecules could affect AD-like cognitive impairments of rodents. For this purpose, we induced memory deficits in 8.5-week-old Imprinting Control Region (ICR) mice (male, $n=9-10$ per group) by injecting $A \beta 42$ aggregates (Fig. 1a,b) into the intracerebroventricular region ${ }^{14}$. This $A \beta$ infusion model allowed us to control the onset of abnormal $A \beta$ deposition before or after the administration of our compounds. Among the six orally administered molecules, only 4-(2hydroxyethyl)-1-piperazinepropanesulphonic acid (EPPS) ameliorated AD-like phenotypes in our mouse model. To assess the cognitive changes of $A \beta$-infusion mice, we performed Y-maze tests and observed alternations of short-term spatial working memory. To examine the prophylactic efficacy of EPPS in this model (pretreatment), EPPS was orally administered for 7 days (30 or $100 \mathrm{mg} \mathrm{kg}^{-1}$ per day) to 8.5 -week-old ICR mice $(n=9-10$ per group) via drinking water, followed by the intracerebroventricular injection of $\mathrm{A} \beta$ aggregates (Supplementary Fig. 1A) and an additional 7-day oral administration of EPPS. In the Y-maze test, EPPS pre-administration blocked the development of $A \beta$-induced memory deficits (Fig. 1c). To assess prompt efficacy (co-treatment) of EPPS, we orally administered EPPS to 8.5-week-old ICR mice ( $n=9-10$ per group) for 5 days (30 or $100 \mathrm{mg} \mathrm{kg}^{-1}$ per day) via drinking water subsequent to the intracerebroventricular injection of $A \beta$ aggregates (Supplementary Fig. 1A). We observed substantial rescue of working memory deficits in $A \beta$-infused mice by EPPS treatment (treatment effects: $30 \mathrm{mg} \mathrm{kg}^{-1}$ per day, $P=0.015 ; 100 \mathrm{mg} \mathrm{kg}^{-1}$ per day, $P=0.006 ;$ Fig. 1d). Collectively, these results imply that EPPS not only inhibits $A \beta$ aggregation but also mediates $A \beta$-induced cognitive impairments.

EPPS is orally safe and penetrates the blood-brain barrier. Before conducting further in vivo studies of therapeutic potentials, we measured the toxicity and pharmacokinetics profiles of EPPS. Toxicity and pharmacokinetics are crucial features of $\mathrm{AD}$ therapeutics, as long-term treatment is often required. To examine whether EPPS elicits toxic effects when orally administered, we included EPPS in drinking water for wild-type (WT) mice (4-week-old, male, $n=6$ per group) to determine the half-maximal lethal dosage $\left(\mathrm{LD}_{50}\right)$. Lethal toxicity was measured based on mortality, changes in body weight and hair loss observed over a 2-month period. The oral administration of EPPS did not cause any toxicity up to $2,000 \mathrm{mg} \mathrm{kg}^{-1}$ per day of administration $\left(\mathrm{LD}_{50}>2,000 \mathrm{mg} \mathrm{kg}^{-1}\right.$ per day). To investigate the ability of EPPS to penetrate the blood-brain barrier, we performed pharmacokinetics profiling in SpragueDawley (SD) rats (male, $n=9$ per group; Supplementary Table 1). We orally administered EPPS $\left(0,10\right.$ or $100 \mathrm{mg} \mathrm{kg}^{-1}$ per day) via drinking water for 7 consecutive days ${ }^{5}$. During the administration, we did not observe any obvious abnormal behaviours or physical changes. Blood $(500 \mu \mathrm{l})$ and brain samples were collected at 24,72, 120 and 168 hours. As the structure of EPPS lacks a chromophore detectable in highperformance liquid chromatography, concentrations of EPPS in the plasma and brain samples were determined using mass spectrometry. The chromatographic conditions showed that the blank plasma or brain homogenate had no interference in the EPPS determination. We found that the brain concentration of EPPS (10 $\mathrm{mg} \mathrm{kg}^{-1}$ per day) reached its plateau $\left(7.52 \mathrm{ngg}^{-1}\right)$ within 72 hours and sustained a brain/plasma level of $2.04 \mathrm{ml} \mathrm{g}^{-1}$ (Supplementary Table 2). At a dose of $100 \mathrm{mg} \mathrm{kg}^{-1}$ per day, we a

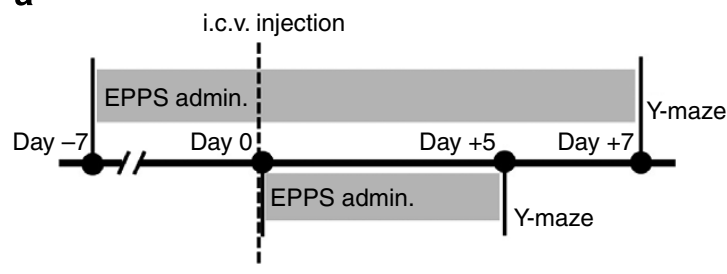

b

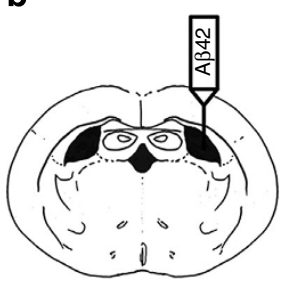

C

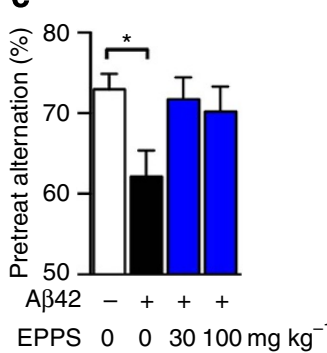

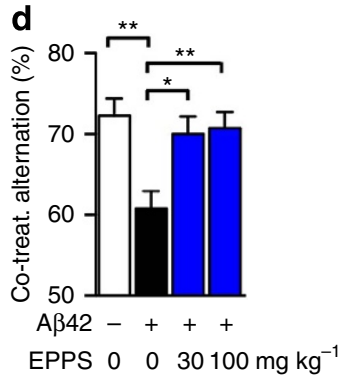

Figure 1 | EPPS ameliorates A $\boldsymbol{\beta}$-induced memory deficits in mice. (a) Time course of the experiments. (b) Intracerebroventricular (i.c.v.) injection site brain schematic diagram. (c) Pretreated effects of EPPS on A $\beta$-aggregate-induced memory deficits observed by the \% alternation on the Y-maze. EPPS, $O(n=10), 30(n=9)$ or $100 \mathrm{mg} \mathrm{kg}^{-1}$ per day $(n=10)$, was orally given to 8.5 -week-old ICR male mice for 1 week; then, vehicle (10\% DMSO in PBS, $n=10$ ) or $A \beta$ aggregates ( 50 pmol per $10 \%$ DMSO in PBS; Supplementary Fig. $1 A$ ) were injected into the intracerebroventricular region $(P=0.022)$. (d) Co-treated effects of EPPS on A $\beta$-aggregate-induced memory deficits observed by the \% alternation on the Y-maze. Male, 8.5-week-old ICR mice received an injection of vehicle $(n=9)$ or $\mathrm{A} \beta$ aggregates into the intracerebroventricular region, and then $\operatorname{EPPS}, 0(n=10), 30(n=10)$ or $100 \mathrm{mg} \mathrm{kg}{ }^{-1}$ per day $(n=10)$, was orally given to these mice for 5 days. From the top, $P=0.003,0.006,0.015$. The error bars represent the s.e.m. One-way analysis of variance followed by Bonferroni's post-hoc comparisons tests were performed in all statistical analyses. $\left({ }^{\star} P<0.05,{ }^{\star \star} P<0.01,{ }^{\star \star \star} P<0.001 ;\right.$ other comparisons were not significant). 
observed that the EPPS brain/plasma level $\left(0.342 \mathrm{mlg}^{-1}\right)$ was relatively lower than that of rats with $10 \mathrm{mg} \mathrm{kg}^{-1}$ per day administration of EPPS, despite the higher brain concentration. Collectively, orally administered EPPS lacked evident toxicity after daily $2,000 \mathrm{mg} \mathrm{kg}^{-1}$ per day dosing for 2 months and maximal brain/plasma levels have been achieved at doses lower than $100 \mathrm{mg} \mathrm{kg}^{-1}$ per day. Based on these results, we decided to orally administer $10-100 \mathrm{mg} \mathrm{kg}^{-1}$ per day EPPS dosages to mice for the in vivo experiments, including behavioural tests and brain analyses.

Orally administered EPPS rescues cognitive deficits in APP/PS1 mice. To test the therapeutic efficacy of orally administered EPPS in a symptomatic transgenic (TG) animal model of AD, we used aged APPswe/PS1-dE9 (amyloid precursor protein/presenilin protein 1 (APP/PS1)) double-TG model mice (10.5-month-old, male; Fig. 2a). The APP/PS1 model produces elevated levels of human $A \beta$ by expressing mutant human APP and PS1. This model is known to develop AD-like phenotypes from 5 months of age ${ }^{15}$. Before EPPS administration, we observed severe cognitive deficits and large amounts of plaques in the 10.5 -month-old APP/PS1 mice (male, $n=13$ ) by Y-maze tests $(P<0.0001$; Fig. 2b) and brain plaque staining (Fig. 4a), respectively.
EPPS was included in drinking water, starting at 10.5 months until 14 months of age. After the daily oral administration of EPPS ( 10 and $30 \mathrm{mg} \mathrm{kg}^{-1}$ per day; $n=11$ and 8 , respectively) or water (non-treated, $n=15$ ) for 3 months, mice were subjected to behavioural analyses, to monitor cognitive function. EPPS was continuously administered over the span of 2 weeks during the Y-maze, fear conditioning and Morris water maze tests (Fig. 2a). For comparison, age-matched WT mice (14-month-old, male, $n=16$ ) were also subjected to behavioural tests. These behavioural tests examine hippocampal functionality, which is one of the earliest and most acutely affected brain regions in $\mathrm{AD}^{16}$. Cognitive ability was determined as the per cent alternation on the Y-maze. We found that EPPS treatment significantly improved behavioural performance on the Y-maze test when compared with non-treated, age-matched TG mice (treatment effect, $P=0.008$ and $0.010 ; 10$ and $30 \mathrm{mg} \mathrm{kg}^{-1}$ per day, respectively; Fig. 2c). The total number of individual arm entries was not altered by EPPS treatment; all cohorts of mice performed equally well in the Y-maze test (Fig. 2d). Next, the emotion-associated learning ability based on amygdalahippocampal communication was assessed by measuring the freezing response in fear-conditioning tests. EPPS treatment was also found to significantly improve the performance of TG mice in the contextual fear-conditioning tasks compared with

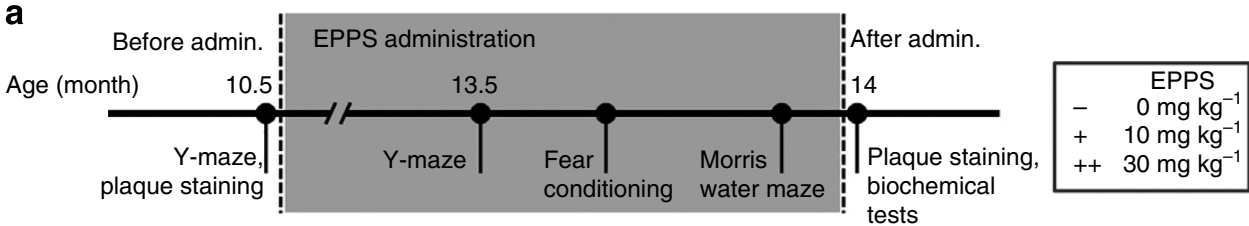

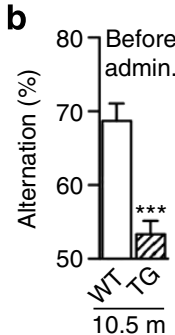
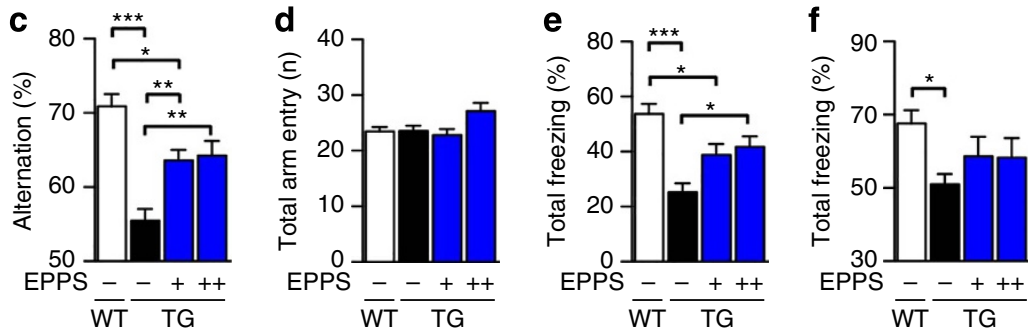

g

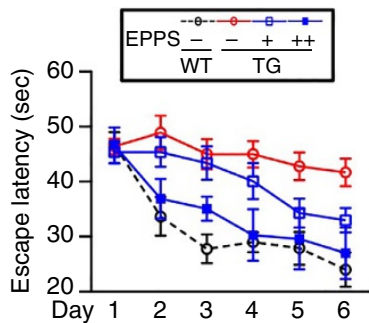

h

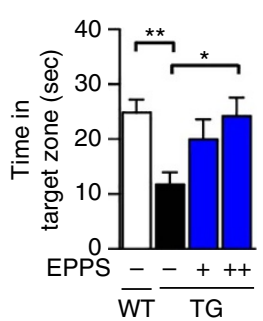

i

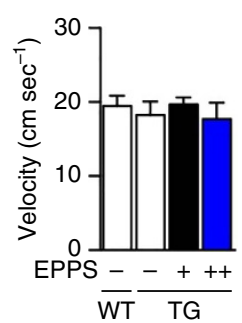

j

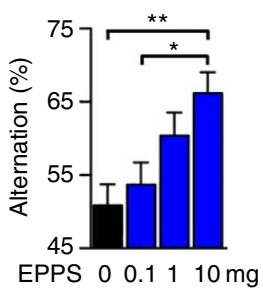

Figure 2 | EPPS rescues hippocampus-dependent cognitive deficits. (a) Time course of behavioural tests. EPPS, $0($ TG $(-)$, male, $n=15), 10($ TG $(+)$, male, $n=11$ ) or $30 \mathrm{mg} \mathrm{kg}^{-1}$ per day $(\mathrm{TG}(++)$, male, $n=8$ ), was orally given to 10.5 -month-old APP/PS1 mice for 3.5 months and their behavioural changes were compared with age-matched WT mice (WT $(-)$, male, $n=16)$. (b) Pre-EPPS treatment evaluation of cognitive deficits; 10.5-month-old WT mice (male, $n=18$ ) and age-matched APP/PS1 TG mice (male, $n=13$ ) were used in Y-maze tests, to obtain the $\%$ alternation before the administration of EPPS. The data indicated cognitive deficits in 10.5-month-old APP/PS1 mice $(P<0.0001)$. (c-i) $Y$-maze, fear-conditioning and Morris water maze tests on 14-month-old APP/PS1 mice after EPPS administration for 3.5 months total. (c) Per cent alternation on Y-maze. From the top, $P=0.000,0.020,0.008$, 0.010. (d) Total entry number into each arm of the Y-maze test. (e) Per cent total freezing from contextual fear conditioning. From the top, $P=0.000$, 0.036, 0.038. (f) Per cent total freezing in the cued task, $P=0.025$. (g) Hidden platform test (significances, see Supplementary Table 3) and (h) the probe test in the Morris water maze, $P=0.003,0.033$. (i) Swim speeds of the probe test (crossing number of located hidden platform analysis, see Supplementary Fig. 2I). (j) Dose-dependent evaluation of EPPS-induced memory alterations. EPPS was orally given to 12-month-old APP/PS1 TG male mice in $0,0.1,1$ or $10 \mathrm{mg} \mathrm{kg}^{-1}$ per day $(n=7-9)$ dosages for 3 months. Per cent alternation on Y-maze $(P=0.005,0.041)$. The error bars represent the s.e.m. One-way analysis of variance followed by Bonferroni's post-hoc comparisons tests were performed in all statistical analyses $\left({ }^{\star} P<0.05,{ }^{\star \star} P<0.01\right.$,

${ }^{\star \star \star} P<0.001$; other comparisons were not significant). 

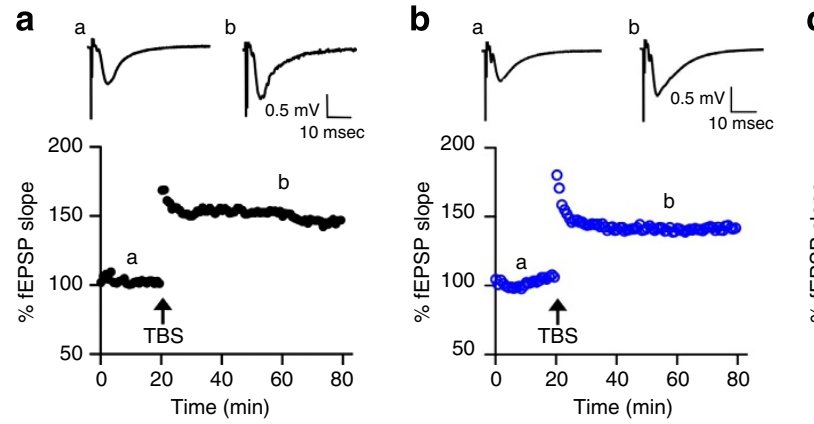

c
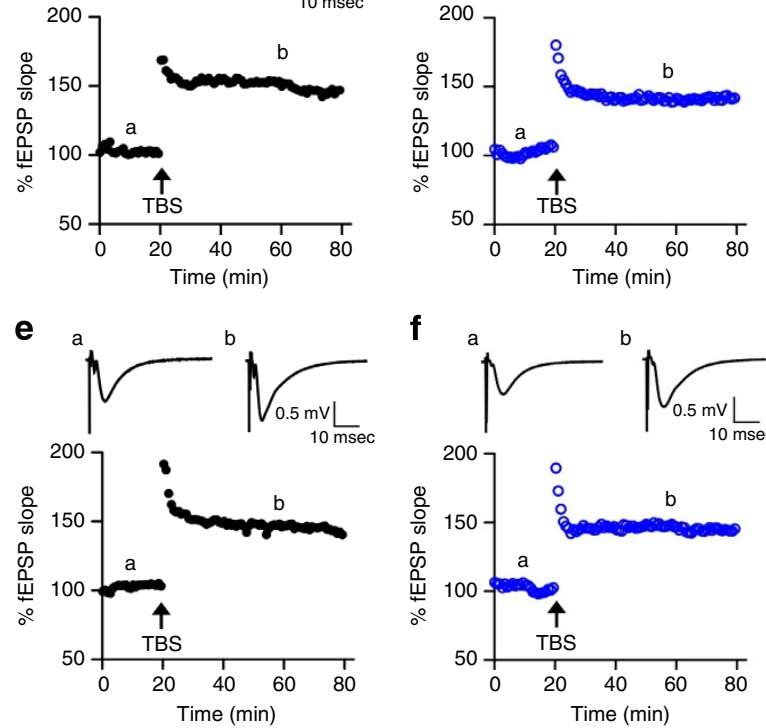

f

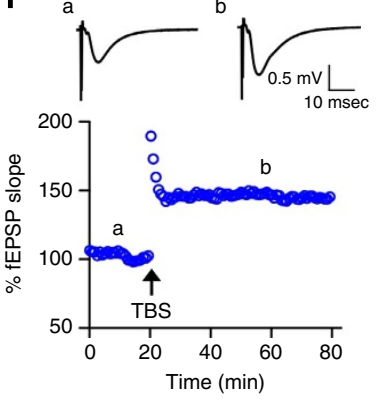

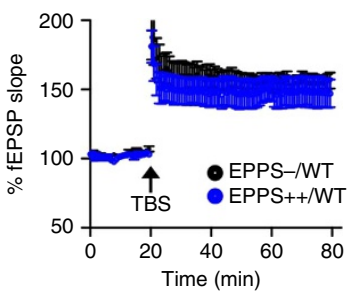

g

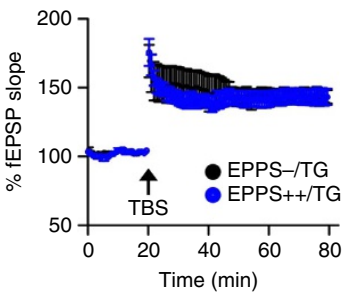

d

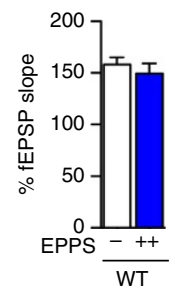

h

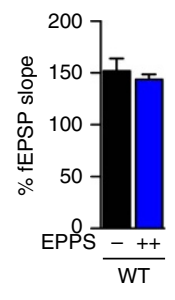

Figure 3 | EPPS does not affect synaptic plasticity in mice. EPPS, O (EPPS - ) or $30 \mathrm{mg} \mathrm{kg}^{-1}$ per day (EPPS ++ ), was orally given to WT ( $\left.n=4\right)$ and APP/PS1 TG $(n=4)$ mice for 5 days. (a-d) LTP, measured by \% field EPSP\% fEPSP slope, in CA1 of hippocampal slices (three slices per mouse) from WT mice. (a) Upper trace, a representative trace of fEPSP before and after inducing LTP by pairing stimuli in CA1 of the hippocampus in non-treated mice. Lower trace, a time course of EPSP before and after inducing LTP by pairing stimuli in CA1 of the hippocampus in non-treated mice. (b) Upper trace, a representative trace of EPSP before and after inducing LTP by pairing stimuli in CA1 of the hippocampus (three slices per mouse) in EPPS-treated mice. (c) Averaged time course of EPSP before and after inducing LTP by pairing stimuli in CA1 of the hippocampus in non-treated and EPPS-treated mice.

(d) Quantification of the effect of EPPS on LTP. (e-h) LTP, measured by the \% fEPSP slope, in CA1 of hippocampal slices from TG mice. (e) Upper trace, a representative trace of EPSP before and after inducing LTP by pairing stimuli in CA1 of the hippocampus in non-treated mice. Lower trace, a time course of EPSP before and after inducing LTP by pairing stimuli in CA1 of the hippocampus in non-treated mice. (f) Upper trace, a representative trace of EPSP before and after inducing LTP by pairing stimuli in CA1 of the hippocampus in EPPS-treated mice. ( $\mathbf{g}$ ) Averaged time course of EPSP before and after inducing LTP by pairing stimuli in CA1 of the hippocampus in saline-treated and EPPS-treated mice. (h) Quantification of EPPS effect on LTP in TG mice. LTP was induced by theta burst stimulation (TBS), represented by the arrow. The error bars represent the s.e.m. Student's unpaired $t$-tests were performed in statistical analyses; comparisons were not significant $(P>0.05)$.

non-treated TG controls and was improved to a level similar to that of the WT mice (treatment effect, $P=0.036$ and 0.038 ; 10 and $30 \mathrm{mg} \mathrm{kg}^{-1}$ day, respectively; Fig. 2e). We did not observe significant behavioural improvement in APP/PS1 by EPPS in cued fear-conditioning tasks (Fig. 2f). Finally, in the Morris water maze task, EPPS-treated TG mice also showed significant cognitive recovery compared with non-treated, age-matched TG mice (treatment effects: $30 \mathrm{mg} \mathrm{kg}^{-1}$ day; 4-day training effect, $P=0.088$; 6-day training effect, $P=0.019$; Fig. $2 \mathrm{~g}-\mathrm{i}$, Supplementary Fig. 2I and Supplementary Table 3), suggesting that EPPS treatment ameliorates spatial memory deficits in this model. As we did not observe dose-dependent therapeutic efficacy between EPPS-treated groups with 10 and $30 \mathrm{mg} \mathrm{kg}^{-1}$ day doses, we lowered the administration dosages of EPPS to 0, 0.1, 1 and $10 \mathrm{mg} \mathrm{kg}^{-1}$ day, and orally administered these doses to 12-month-old APP/PS1 mice for 3 months (male, $n=8,7,8$ and $9 ; 0,0.1,1$ and $10 \mathrm{mg} \mathrm{kg}^{-1}$ day, respectively). In the Y-maze test, EPPS improved cognitive deficits in a dose-dependent manner in these mice (treatment effect, $P=0.005$ and 0.041 ; 0 versus $10 \mathrm{mg} \mathrm{kg}^{-1}$ day and 0.1 versus $10 \mathrm{mg} \mathrm{kg}^{-1}$ day, respectively; Fig. 2j).

To address the possibility that EPPS directly activates the cognitive abilities of mice without altering the APP/PS1-related neuropathology of $\mathrm{AD}$, we examined changes in the cognitive behaviours and synaptic plasticity of WT C57BL/6 mice. When we orally administered EPPS to 10.5-month-old WT mice for 3.5 months (male, $n=10$ per group), we did not observe cognitive enhancement in Y-maze, fear-conditioning and Morris water maze tests (Supplementary Fig. 2A-H). To physiologically assess the effects of EPPS on long-term potentiation (LTP) in the WT (Fig. 3a-d) and APP/PS1 mice (Fig. 3e-h), we performed electrophysiology experiments and measured excitatory postsynaptic potential (\% EPSP) in acute hippocampal slices (three slices per mouse) prepared from EPPS- and water-administered mice. At the Schaffer collateral (SC) inputs to hippocampal CA1, LTP of both WT (\% EPSP increase by pairing stimuli: $158.2 \pm 7.1 \%$ for non-treated group (EPPS-/WT), $n=4$; $149.3 \pm 10.1 \%$ for treated group (EPPS $++/ \mathrm{WT}), n=4)$ and APP/PS1 (\% EPSP increase by pairing stimuli: $152.0 \pm 12.3 \%$ for non-treated group (EPPS - /TG), $n=4 ; 143.6 \pm 5.0 \%$ for treated group (EPPS $++/ \mathrm{TG}), n=4)$ mice was not affected by orally administered EPPS ( $30 \mathrm{mg} \mathrm{kg}^{-1}$ per day for 5 days) compared with non-treated controls (Fig. 3). These results imply that EPPS neither affects LTP nor enhances general learning and memory abilities of cognitively normal mice.

Collectively, these results indicate that EPPS rescues hippocampus-dependent cognitive deficits when orally administered to aged, symptomatic APP/PS1 TG mice.

EPPS removes A $\beta$ plaques and oligomers in APP/PS1 mice. All of the aforementioned APP/PS1 and WT mice were killed after behavioural tests and had their brains examined in histochemical and blotting analyses. To examine the effect of orally 
administered EPPS on the amount of $A \beta$ plaques and oligomers in the brain, brains of non-treated APP/PS1 mice were sectioned and then stained with thioflavin $\mathrm{S}$ (ThS) to visualize dense-core $A \beta$ plaques ${ }^{17}$ (Fig. 4a). Compared with 10.5-month-old APP/PS1 brains, we observed a significant increase in $A \beta$ plaques, twofold in number and threefold in area, throughout the entire brain of 14-month-old APP/PS1 mice $(P<0.0001$; Fig. $4 \mathrm{a}, \mathrm{b})$. By contrast, EPPS treatment reduced the levels of A $\beta$ plaques in APP/PS1 mice in a dose-dependent manner (treatment effect, $P<0.0001$ for both 10 and $30 \mathrm{mg} \mathrm{kg}^{-1}$ per day; Fig. 4a,b) and substantially eliminated $A \beta$ plaques in the hippocampus at the dose of $30 \mathrm{mg} \mathrm{kg}^{-1}$ per day $\left(\mathrm{EC}_{50}=5.22 \mathrm{mg} \mathrm{kg}^{-1}\right.$ per day; Fig. $\left.4 \mathrm{~b}\right)$.

As an independent measure of $A \beta$ levels, we performed sandwich enzyme-linked immunosorbent assay (ELISA; Fig. 4c,d). To separately analyse levels of insoluble and soluble $A \beta$, hippocampal and cortical regions were lysed using guanidine (insoluble fraction) or sucrose lysis (soluble fraction) buffers. As a result, we found a dose-dependent reduction of insoluble $A \beta$ in the brains of EPPS-treated APP/PS1 mice (hippocampus, $P<0.0001$ for both 10 and $30 \mathrm{mg} \mathrm{kg}^{-1}$ per day; cortex, $P=0.046$ and $0.004,10$ and $30 \mathrm{mg} \mathrm{kg}^{-1}$ per day, respectively; Fig. 4c), which was similar to ThS histochemistry results (Fig. 4a,b). On the contrary, we did not observe a significant decrease in the level of soluble A $\beta$ species by EPPS (Fig. 4d). Soluble $A \beta$ in the sucrose lysis buffer could comprise both monomers and oligomers. To assess the level of $A \beta$ oligomers, we performed dot blot assays on brain lysates using $6 \mathrm{E} 10$ and A11 antibodies. The $6 \mathrm{E} 10$ antibody detects all $A \beta$ species and recognizes APP, whereas A11 detects oligomeric proteins in soluble fractions. EPPS dose dependently decreased the amount of oligomeric species but the concentration of total soluble $A \beta$, which includes monomers, did not change (Fig. 4e).

Previous clinical investigations suggested that ThS-negative diffuse $A \beta$ plaques were an early pathological sign of $A D^{18,19}$. To eliminate the possibility that EPPS only loosened $\beta$-sheet-rich aggregates into less dense diffuse plaques, we performed $A \beta$ immunohistochemistry using the anti- $\mathrm{A} \beta 6 \mathrm{E} 10$ antibody $^{20}$. In contrast to ThS, $6 \mathrm{E} 10$ can stain both dense core and diffuse plaques in brain tissues. Fluorescent microscopy illustrated that ThS- and 6E10-stained plaques precisely co-localized in the hippocampal region and were equally reduced by EPPS treatment in a dose-dependent manner (Fig. 4f). We did not observe ThSnegative diffuse plaques in EPPS-treated APP/PS1 mice. To examine whether the oral administration of EPPS affected the expression levels of APP, we performed western blot analyses. In the hippocampal and cortical regions of APP/PS1 mice, the levels of APP were similar between the water- and EPPS-treated groups (Fig. 4g and Supplementary Fig. 3A). Neuropathological development of $\mathrm{AD}$ based on gender differences has previously been reported ${ }^{21,22}$. Female APP/PS1 mice deposit $A \beta$ earlier than age-matched male mice and the cause of the difference is unclear. To examine whether EPPS exerted similar effects on female mice, EPPS (30 $\mathrm{mg} \mathrm{kg}^{-1}$ per day) was included in drinking water and provided to female APP/PS1 mice (10.6-month-old, $n=6$ per group) for 1 month. Consistent with the results from male APP/ PS1 mice, EPPS treatment similarly and significantly reduced A $\beta$ plaques in the brains of female TG mice (plaque number and area, $P<0.0001$; Supplementary Fig. 4). Collectively, these results indicate that orally administered EPPS effectively decreases $A \beta$ plaques and oligomers in APP/PS1 model mouse brains.

EPPS lowers A $\beta$-dependent inflammation and glial GABA release. $A \beta$-dependent inflammation generally reflects the extent of injury and toxicity in $\mathrm{AD}^{23}$. Thus, we examined whether EPPS treatment affected inflammation by immunohistochemistry of male APP/PS1 mouse brains from the aforementioned behavioural studies. EPPS treatment markedly reduced the levels of c-Jun N-terminal kinase (JNK) phosphorylation, astrocytosis (GFAP, glial fibrillary acidic protein) and microgliosis (Iba-1, ionized calcium-binding adaptor molecule-1) to the level of WT mice. On the contrary, the phosphorylation of cyclic AMP response element-binding protein, which is related to memory enhancement in AD, was increased ${ }^{2,24}$ (Fig. 5a and Supplementary Fig. 3B,C). In addition, large reductions in plaques, astrocytosis and microgliosis were confirmed by immunohistochemistry (Fig. 5b). These data show that the aberrant elevation of inflammation found in APP/PS1 TG mice was reduced after oral administration of EPPS.

Previously, we reported that reactive astrocytes abundantly produced and released the inhibitory gliotransmitter $\gamma$-aminobutyric acid (GABA) by the stimulation of $A \beta$ aggregates, and that the suppression of tonic glial GABA release recovered synaptic plasticity and cognitive deficits in APP/PS1 TG mice ${ }^{25}$. In this study, we measured EPPS-induced alterations of the tonic GABA release from reactive astrocytes in aged APP/PS1 mice by immunohistochemistry (Fig. 5c). We observed that daily treatment of EPPS (30 $\mathrm{mg} \mathrm{kg}^{-1}$ per day) significantly reduced the levels of GABA around reactive astrocytes (GFAP stained) in the hippocampal region of APP/PS1 mice to a level similar to that of WT (treatment effects, $P<0.0001$ for both 10 and $30 \mathrm{mg} \mathrm{kg}^{-1}$ per day, Fig. $5 \mathrm{~d}, \mathrm{e})$. These results support the view that the elimination of $A \beta$ plaques by agents such as EPPS suppresses the abnormal tonic release of GABA from reactive astrocytes and recovers memory impairments.

EPPS disaggregates A $\beta$ oligomers and fibrils by direct interaction and reduces cytotoxicity. To understand how EPPS reduces amyloid deposits and recovers cognitive deficits in mouse models, we investigated interactions between EPPS and A $\beta$ aggregates by in vitro biochemical and biophysical assays. Previously, we reported that EPPS inhibited the de novo formation of $\mathrm{A} \beta$ oligomers and fibrils in thioflavin-T (ThT), SDS-polyacrylamide gel electrophoresis (SDS-PAGE) and transmission electron microscopy ${ }^{13}$. In this study, we prepared $A \beta$ oligomers and fibrils through the preincubation of the peptide and monitored EPPS-induced alterations to these aggregates using ThT, SDS-PAGE and transmission electron microscopy. We performed a cell-free ThT fluorescence assay to detect ThT bound to a $\beta$-sheet complex, which is proportional to the amount of $A \beta$ fibril ${ }^{10,26}$. Preformed aggregates of the two most common $A \beta$ types, $A \beta 42$ and $A \beta 40$, were incubated with or without candidate molecules for $1,2,3$ and 7 days. EPPS dose dependently disaggregated $\beta$-sheet-rich preformed $A \beta$ fibrils (Fig. 6a and Supplementary Fig. 5A). The ThT fluorescence assay can produce false-positive results when, for example, EPPS binds to ThT and interferes with the complex formation between ThT and $\mathrm{A} \beta$ fibrils, leading to a decrease in ThT fluorescence intensity ${ }^{26}$. To circumvent this issue, we directly visualized insoluble $A \beta$ fibrils using transmission electron microscopy in the presence and the absence of EPPS. We found that a 7-day treatment of EPPS completely disaggregated the hair-like $A \beta$ fibril structures (Fig. 6b and Supplementary Fig. 5B). Among A $\beta$ aggregates, soluble oligomers, including dimers and trimers, are reported to be the most neurotoxic species ${ }^{3,27,28}$. To test whether EPPS disaggregates harmful $A \beta$ oligomers into non-toxic monomers, we performed SDS-PAGE with photo-induced cross-linking of the unmodified proteins (PICUP), followed by silver staining, which allows us to separate and compare the assembled oligomeric species ${ }^{29}$. We found that EPPS treatment sharply reduced high-molecular-weight aggregates (above $250 \mathrm{kDa}$ ) and oligomeric species, while increasing the concentration of 
a

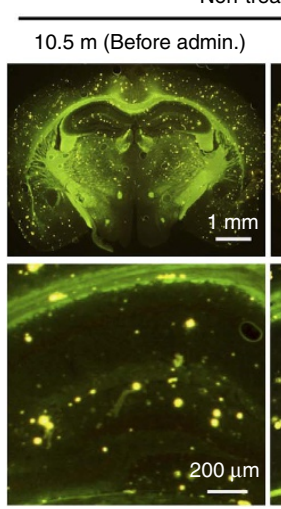

b

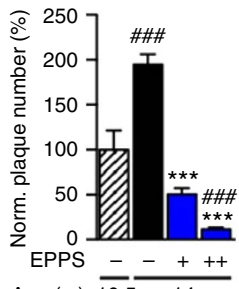

Age (m) $\overline{10.5} 14$

C

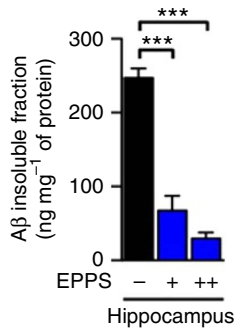

d

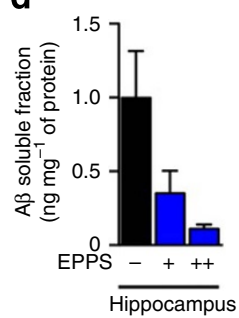

Non-treated TG

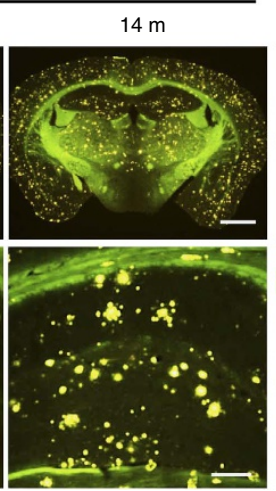

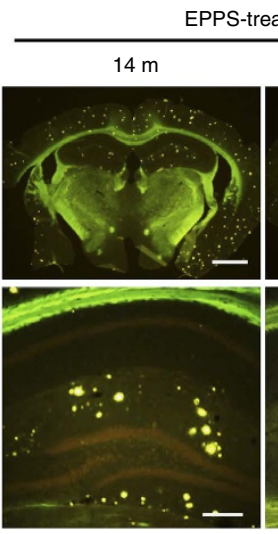
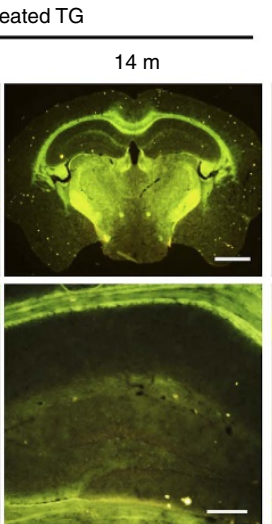
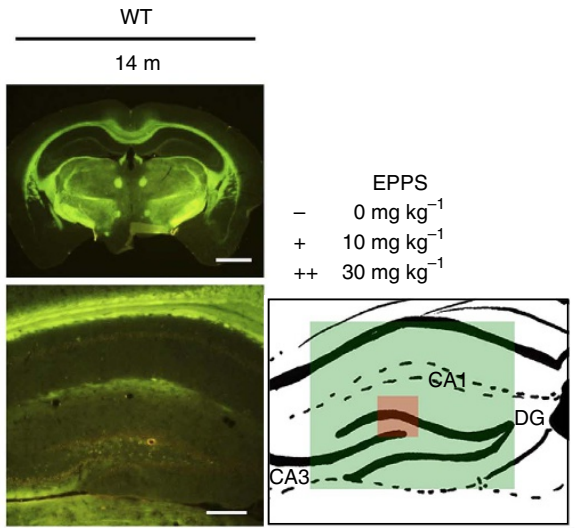

f WT
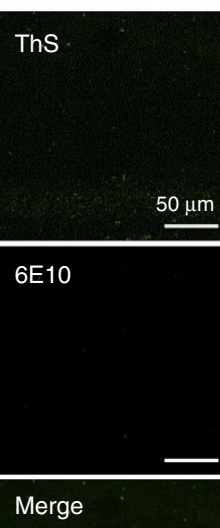

EPPS 1 - 1

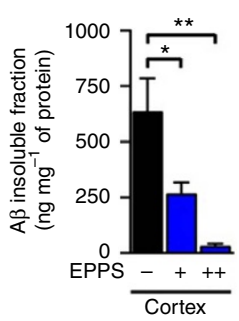

e
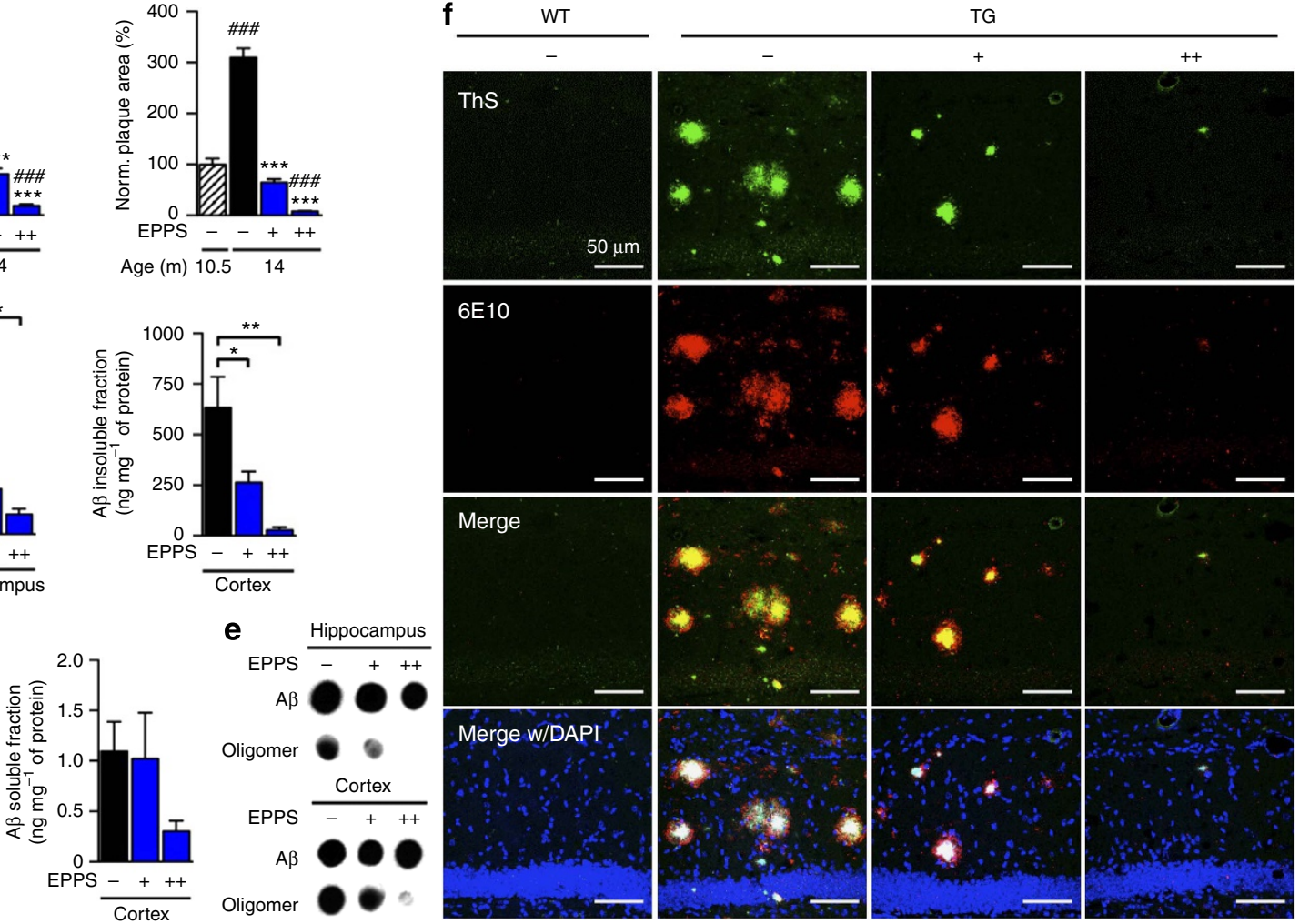

g
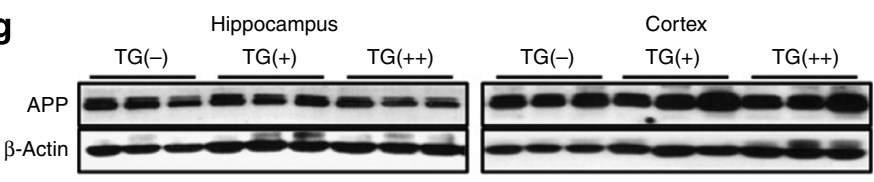

Figure 4 I EPPS disaggregates A $\boldsymbol{\beta}$ plaques and oligomers in APP/PS1 mice. APP/PS1 mice and WTs from the aforementioned behavioural tests were killed and subjected to brain analyses. EPPS, $0(\mathrm{TG}(-)$, male, $n=15), 10(\mathrm{TG}(+)$, male, $n=11)$ or $30 \mathrm{mg} \mathrm{kg}^{-1}$ per day $(\mathrm{TG}(++)$, male, $n=8)$, was orally given to 10.5-month-old APP/PS1 for 3.5 months and their brains were compared with age-matched WT brains (WT( - ), male, $n=16)$. (a) ThS-stained A $\beta$ plaques in whole brains (scale bars, $1 \mathrm{~mm}$ ) and the hippocampal region (scale bars, $200 \mu \mathrm{m}$ ) of each group. The mouse brain schematic diagram was created by authors (green and red boxes: regions of brain images, a and $\mathbf{f}$, respectively). (b) Number or area of plaques normalized (\%) to the level in 10.5month-old TG mice. Plaque number: P-values compared with TG (male, 10.5-month-old) are all <0.0001 (\#). P-values compared with TG( - ) (male, 14 month-old) are all $<0.0001\left(^{\star}\right)$. Plaque area: $P$-values compared with TG (male, 10.5-month-old) are all $<0.0001$ (\#). P-values compared with TG $(-)$ (male, 14-month-old) are all $<0.0001\left(^{\star}\right)$. (c-e) $A \beta$-insoluble and -soluble fractions analyses from brain lysates. (c) Sandwich ELISA of $A \beta$-insoluble fractions. Hippocampus: all $P<0.0001$; cortex: $P=0.004,0.046$. (d) Sandwich ELISA of $A \beta$-soluble fractions. (e) Dot blotting of the total $A \beta$ (anti-A 3 : 6E10, also recognizes APP) and oligomers (anti-amyloidogenic protein oligomer: A11). (f) Histochemical analyses of $A \beta$ deposition. $A \beta$ s were stained with the 6 E10 antibody and ThS. A $\beta$ plaques (first row): green; all A $\beta$ s (second row): red; 4,6-diamidino-2-phenylindole (DAPI): blue (as a location indicator). The third and bottom rows show merged images of plaques and A $\beta$ s, and plaques and A $\beta$ s with DAPI staining. Scale bars, $50 \mu \mathrm{m}$. (g) Western blotting analyses of APP expression in hippocampal and cortical lysates (detected at $\sim 100$ kDa by 6 E10 antibody). Densitometry (see Supplementary Fig. 3A). Full version (see Supplementary Fig. 7). The error bars represent the s.e.m. One-way analysis of variance followed by Bonferroni's post-hoc comparisons tests were performed in all statistical analyses $\left({ }^{\star} P<0.05,{ }^{\star \star} P<0.01,{ }^{\star \star \star} P<0.001,{ }^{\#} P<0.05,{ }^{\# \#} P<0.01,{ }^{\# \# \#} P<0.001\right.$; other comparisons were not significant). 
a

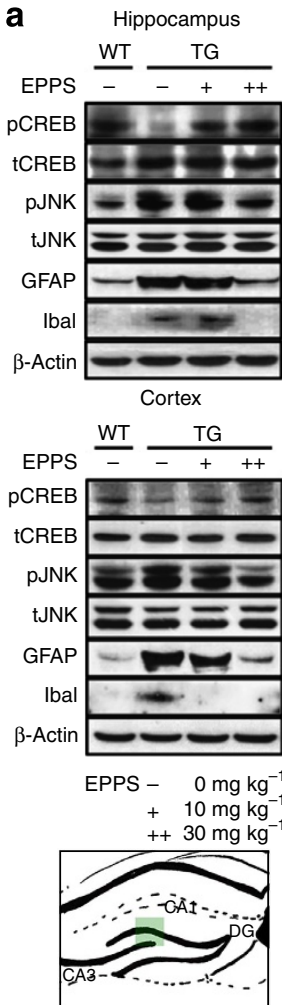

d

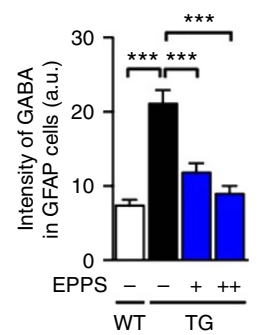

e

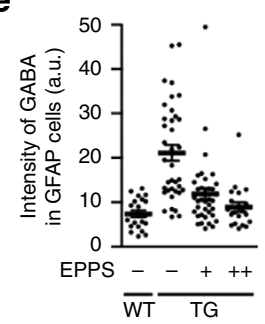

b
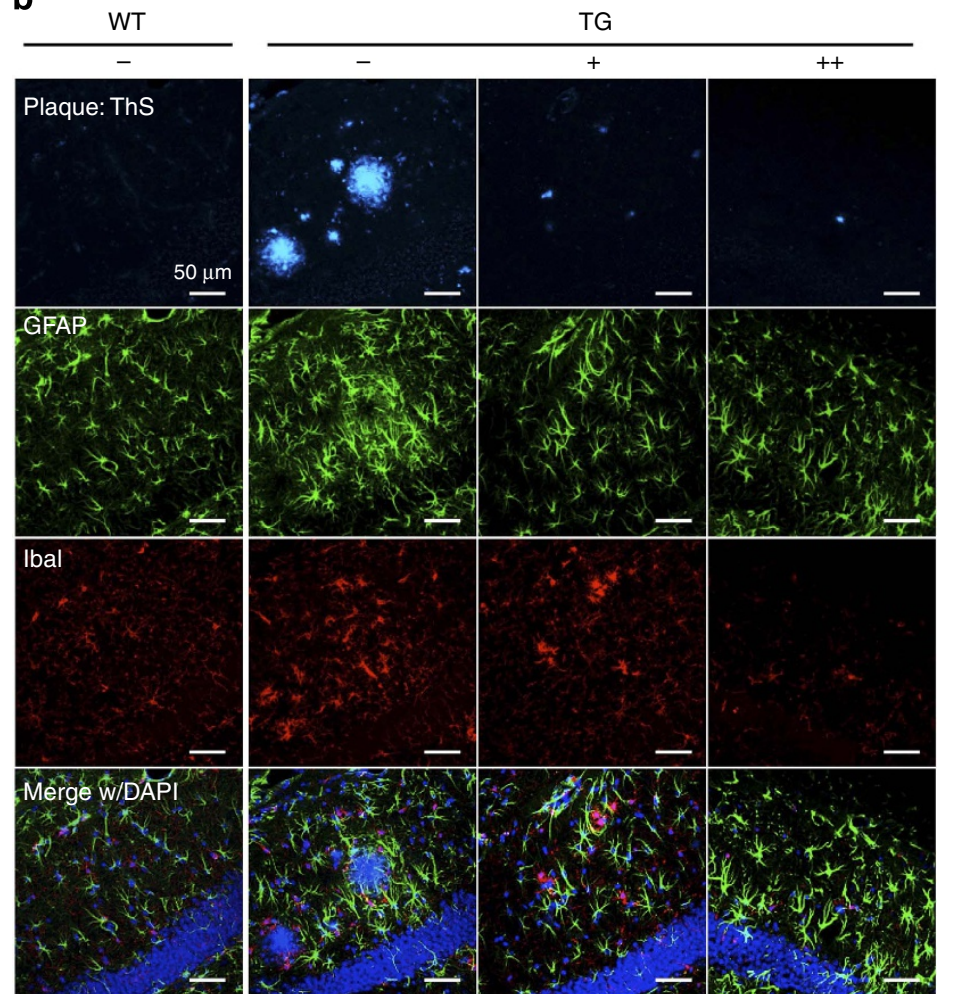

C
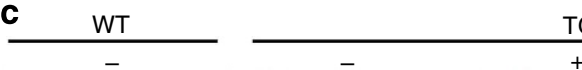

TG

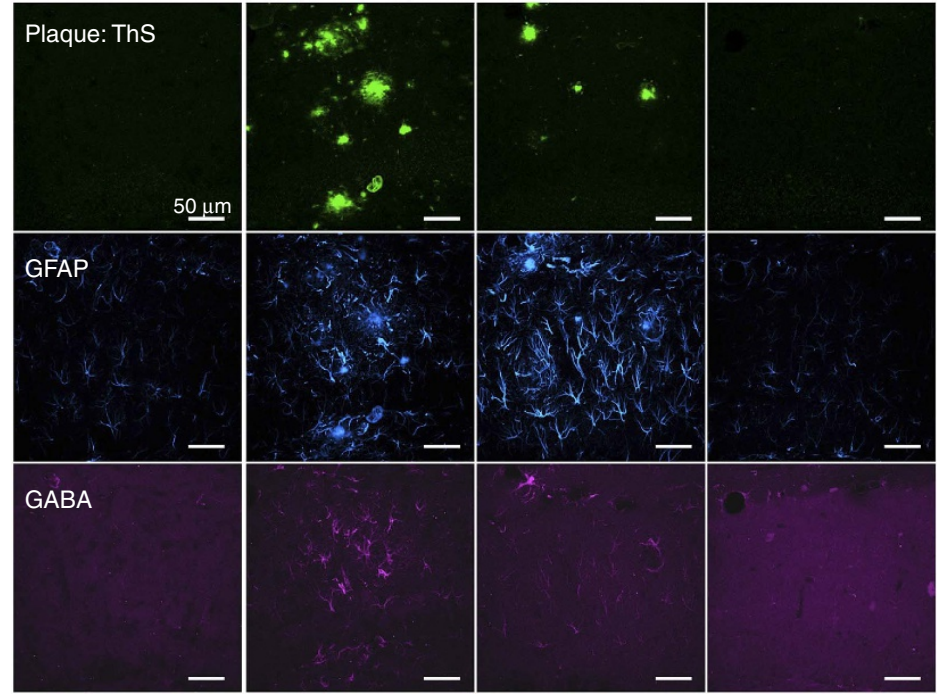

Figure 5 | EPPS lowers inflammation and glial GABA release. APP/PS1 and WT mice from the aforementioned behavioural tests were killed and subjected to brain analyses. EPPS, $0(\mathrm{TG}(-)$, male, $n=15), 10(\mathrm{TG}(+)$, male, $n=11)$ or $30 \mathrm{mg} \mathrm{kg}^{-1}$ per day $(\mathrm{TG}(++)$, male, $n=8)$, was orally given to 10.5-month-old APP/PS1 for 3.5 months and their brains were compared with age-matched WT brains (WT( - ), male, $n=16)$. (a) Western blotting of phosphorylation of cyclic AMP response element-binding protein (pCREB), pJNK, GFAP and Iba-1 (densitometry, see Supplementary Fig. 3B, C). Full version (see Supplementary Fig. 8). (b-e) Histochemical analyses of A $\beta$ deposition, GFAP, Iba-1 and GABA. (b) A $\beta$ plaques stained with ThS (first row): blue; GFAP (second row): green; lba-1 (third row): red; and 4,6-diamidino-2-phenylindole (DAPl; fourth row): blue (as a location indicator). The bottom row shows merged images of plaques, GFAP and Iba-1 with DAPI staining. (c) A $\beta$ plaques stained with ThS (first row): green; GFAP (second row): blue; and GABA (third row): violet. Scale bars, $50 \mu \mathrm{m}$. (d) Quantification of GABA in confocal images ${ }^{25}$. Each dot represents the number of GFAP-positive cells with GABA; a.u., arbitrary unit. (e) GABA average from the previous panel $(P<0.0001$ for all). Values refer to GFAP-positive GABA. The error bars represent the s.e.m. One-way analysis of variance followed by Bonferroni's post-hoc comparison tests were performed in the statistical analysis ( ${ }^{\star \star \star} P<0.001$; other comparisons were not significant). The mouse brain schematic diagram was created by authors (green box: region of brain images).

monomers, suggesting that EPPS may disaggregate A $\beta 42$ and A $\beta 40$ aggregates (Fig. 6c, Supplementary Fig. $1 \mathrm{~B}$ and Supplementary Fig. 5C). As SDS provides a denaturing environment that may allow for the dissociation of protein aggregates on a gel in spite of cross-linking, we used sizeexclusion chromatography (SEC) on high-performance liquid 


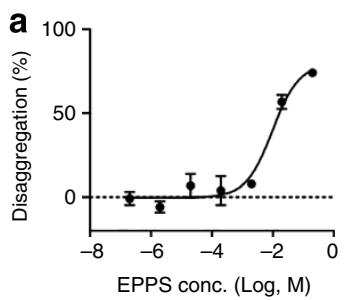

C

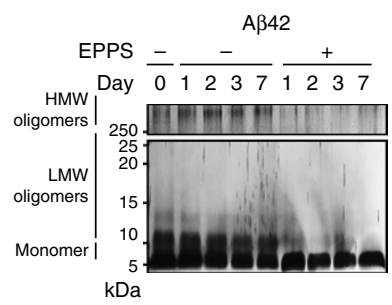

e

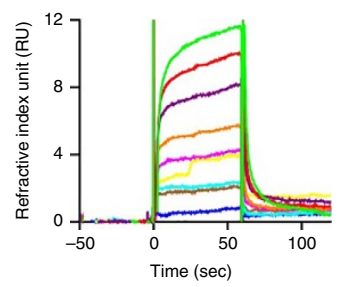

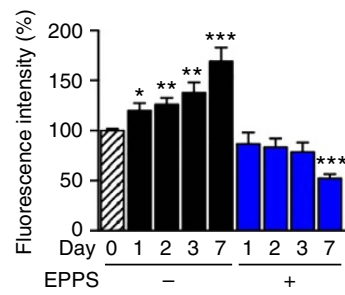

b

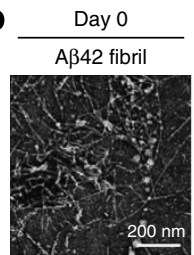

d

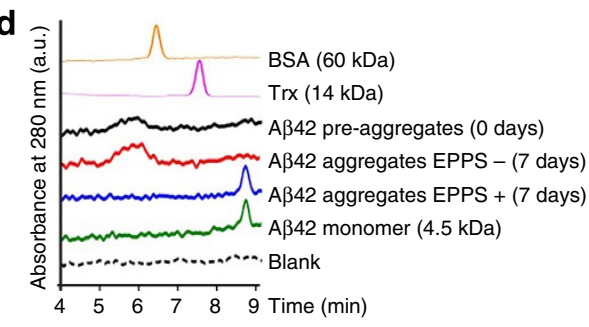

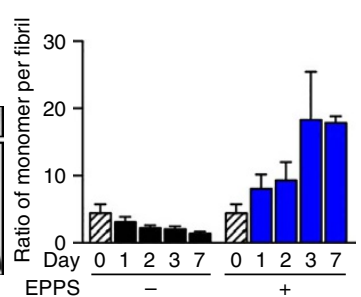

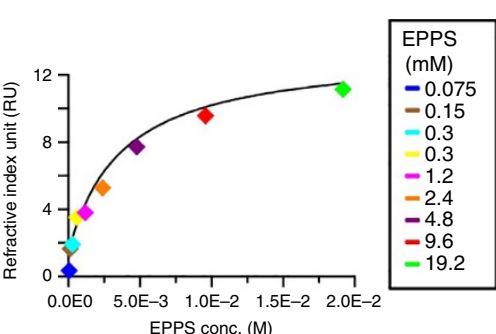

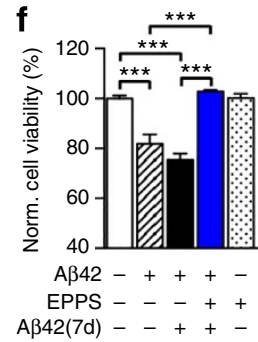

Figure 6 | EPPS disaggregates A $\beta$ aggregates by selective binding. (a-c) Preformed A $\beta 42$ aggregates ( $25 \mu$, Day 0$)$ were incubated with EPPS. (a) EPPS concentration-dependent (200, 20,2,0.2,0.02, $0.002,0.0002$ or $0 \mathrm{mM}$ of EPPS, 3-day treatment) and incubation time-dependent (20 mM EPPS for 1, 2, 3 and 7 days) ThT assays. Fluorescence intensity was normalized to preformed A $\beta$ aggregates (100\%, Day 0). Statistical comparisons were made with day $0(n=4$, Student's $t$-test; from the left: $P=0.034,0.004,0.005,0.000,0.000)$. (b) Transmission electron microscopic images of EPPS-induced A $\beta$ fibril disassembly. Scale bars, $200 \mathrm{~nm}$. The inset shows the chemical structure of EPPS. (c) Silver staining for the SDS-PAGE analysis of PICUP cross-linked $A \beta$ aggregates and the densitometry analysis in the ratio of monomer to fibril (HMW, high molecular weight; LMW, low molecular weight). Full-length version (see Supplementary Fig. 9). (d) SEC analysis. Size markers: BSA (yellow) and thioredoxin (Trx, pink). Control: A 42 monomer (green). a.u., arbitrary unit. (e) Surface plasmon resonance analyses. Dose-dependent kinetics of EPPS targeting A $\beta 40$ oligomers and the corresponding fitting curve from the saturated region of the sensorgram. (f) MTT assays. A $\beta 42: 2.5 \mu \mathrm{M} \mathrm{A} \beta 42$ aggregates, A $\beta 42(7 \mathrm{~d}$ ): $2.5 \mu \mathrm{M} A \beta 42$ aggregates were incubated for 7 days with/without EPPS $(2 \mathrm{mM})$. HT-22 cells were treated with the prepared samples for 24 hours. Cell viability was normalized to that of the non-treated cells (100\%). All P-values were $<0.0001(n=5)$. The error bars represent the s.e.m. of independent triplicate measurements. One-way analysis of variance followed by Bonferroni's post-hoc comparison tests were performed in the statistical analyses $\left({ }^{\star} P<0.05,{ }^{\star \star} P<0.01,{ }^{\star \star \star} P<0.001\right.$; other comparisons were not significant).

chromatography, to confirm oligomer dissociation by EPPS. Using samples identical to ones subjected to the aforementioned PICUP-SDS experiments, we analysed the changes in A $\beta 42$ oligomer concentrations. Preformed aggregates, aggregates that were incubated for 7 days (EPPS - ) and aggregates that were incubated for 7 day with EPPS treatment (EPPS +) were serially injected into the SEC column, with BSA $(60 \mathrm{kDa})$, thioredoxin $(14 \mathrm{kDa})$ and $\mathrm{A} \beta 42$ monomers $(4.5 \mathrm{kDa})$ as reference size markers (Fig. 6d). All samples were not cross-linked and insoluble species were excluded by filtering before injection. We observed that A $\beta 42$ oligomers larger than $60 \mathrm{kDa}$ were the major component of both preformed aggregation and aggregates with the 7-day additional incubation. Consistent with the results from the electrophoresis study, EPPS treatment lowered the level of these oligomers and increased the amount of monomers.

The reduced amount of oligomers and fibrils strongly suggested that EPPS directly binds to A $\beta$ aggregates. To assess direct interaction between EPPS and A $\beta$ aggregates, we employed a label-free surface plasmon resonance test to determine the bimolecular binding kinetics ${ }^{30}$. We immobilized $A \beta 40$ aggregates and monomers on a CM5 sensor chip surface via amine coupling and allowed EPPS in various concentrations (from 0.075 to $19.2 \mathrm{mM}$ ) to pass over the $A \beta$-coupled surface in a Biacore T200 system. Formation of $A \beta 40$ aggregates was confirmed by SDS-PAGE with PICUP cross-linking before the surface immobilization. Reduction in the intensity of reflected light from the chip on binding and dissociation between EPPS and A $\beta$ was measured. We found that EPPS directly bound to $A \beta$ aggregates, as evidenced by the rapid increase of the binding response during EPPS injection in a dose-dependent manner (Fig. 6e). Although the heterogeneous nature of $A \beta$ aggregates made the calculation of the precise binding constant unfeasible, the substantial curve fitting efficiency $\left(0.286 \mathrm{RU}^{2}\right.$ of calculated $\left.\chi^{2}\right)$ supported the dose-dependent interaction between EPPS and immobilized $A \beta$ aggregates ${ }^{31}$. On the contrary, no significant interaction between EPPS and $A \beta$ monomers was observed (Supplementary Fig. 5D).

To examine the toxicity of EPPS-treated $A \beta$ aggregates, we performed cell viability assays on a cultured mouse hippocampal cell line (HT-22). We prepared preformed $\mathrm{A} \beta$ aggregates $(\mathrm{A} \beta 42=2.5 \mu \mathrm{M}$ and $\mathrm{A} \beta 40=5 \mu \mathrm{M})$ and then treated the HT-22 cells with these aggregates for 24 hours. In addition, the preformed $A \beta$ aggregates were incubated with or without EPPS for 7 days and then the cells were treated with these pretreated aggregates for 24 hours (final concentration of $\mathrm{A} \beta 42(7 \mathrm{~d})=2.5 \mu \mathrm{M}$, $\mathrm{A} \beta 40(7 \mathrm{~d})=5 \mu \mathrm{M}, \mathrm{EPPS}=2 \mathrm{mM})$. EPPS treatment fully rescued 
the cells from death induced by $A \beta 42$ (Fig. 6f) and $A \beta 40$ (Supplementary Fig. 5E). EPPS alone did not induce any significant cell damage (Fig. 6f and Supplementary Fig. 5E). As oxidative stress is associated with cellular and synaptic dysfunctions in $\mathrm{AD}$ brains, we performed a 1,1-diphenyl-2-picrylhydrazyl assay ${ }^{32}$ to assess whether EPPS acts as an antioxidant. However, we did not observe any free radical scavenging properties of EPPS in the assay (Supplementary Fig. 6). Taken together, these results suggest that EPPS markedly disaggregates both toxic oligomers and fibrils into monomers and prevents $A \beta$ induced cell damage by direct binding to $A \beta$ aggregates.

\section{Discussion}

Here we report that (1) a small molecule, EPPS, converts neurotoxic oligomers and plaques into non-toxic monomers by directly binding to A $\beta$ aggregates; (2) orally administered EPPS produces a dose-dependent reduction of $A \beta$ plaque deposits and behavioural deficits in APP/PS1 TG mice, even when administration was delayed until after the pathology was well established; (3) the beneficial effect of EPPS probably operates through an $\mathrm{A} \beta$-related mechanism rather by facilitating cognitive processes; and (4) large doses of EPPS appeared to be well tolerated in initial toxicity studies ${ }^{6,7,33}$. EPPS may integrate the therapeutic advantages of previously described $A \beta$-clearing antibodies with the advantages of anti-amyloidogenic chemicals as a small molecule capable of disaggregating diverse species of oligomeric and fibrillar $A \beta$, ameliorating the development of $A \beta$ plaque pathology and behavioural deficits in APP/PS1 TG mice with early treatment and rescuing the pathology and behavioural deficits with delayed administration. Among the three mechanisms of anti- $A \beta$ immunotherapeutics (solubilization by direct binding to $A \beta$, phagocytosis by activated microglia and activation of $A \beta$ extraction to the blood by peripheral sink), the therapeutic behaviour of EPPS most resembles the solubilization by direct binding to $A \beta$. This strategy recently showed promising clinical indications for preventing or treating $\mathrm{AD}^{34,35}$. Furthermore, the disaggregating mode of action of EPPS generates and leaves monomers that may be essential for physiological brain function ${ }^{8,36-39}$. A recent study reported benefits of $A \beta$ peptides in a multiple sclerosis mouse model by modulating the autoimmune neuroinflammation ${ }^{40}$. Bloodbrain barrier permeability and lower manufacturing cost are also considerable benefits of EPPS compared with antibody drug candidates. Additional studies are warranted to determine whether these favourable actions of EPPS and derivatives will translate into a therapy that might potentially be useful across a range of $\mathrm{AD}$ stages.

The present data further suggest that the disaggregating mode of action of EPPS should be explored in detail. First, the effect of EPPS treatment on cognitive behaviours and neuropathological biomarkers in APP/PS1 mice showed different responses based on dosage. Although the levels of $A \beta$ oligomers and plaques in the brain were reduced in a dose-dependent manner within 10, 30 and $100 \mathrm{mg} \mathrm{kg}^{-1}$ per day treated groups, we did not observe significant differences between these groups in the behavioural studies. Structurally, EPPS shares its amino sulfonic acid group with well-known $A \beta$-regulating molecules, such as tramiprosate and bis-ANS ${ }^{5,13,41,42}$. The sulfonic acid group has been reported to mimic the properties of the sulfate ion that is required for the strong binding of glycosaminoglycans to the HHQK region of $A \beta^{5,41}$. In our previous study, we also found that HEPES containing 2-(4-ethylpiperazin-1-yl)ethanol, which is one carbon short of 2-(4-propylpiperazin-1-yl)ethanol, directly inhibits the formation of $A \beta$ aggregates $^{13}$. However, a further in-depth structure-activity relationship study is required to understand how EPPS selectively targets and disaggregates $A \beta$ oligomers and plaques. It is notable that EPPS requires a relatively higher dose in vitro than in vivo, to disaggregate preformed oligomers and plaques. One explanation of this finding is the requirements for highly concentrated $A \beta$ to be detected in in-vitro conditions ${ }^{5,43,44}$. Compared with the nanomolar concentration of $A \beta$ in the $A D$ brain, a micromolar or even higher concentration of the peptide is needed to visualize aggregates. Thus, the dose of EPPS also increases to disaggregate these aggregates. Another possible hypothetic explanation is the lack of $\mathrm{A} \beta$ clearance mechanisms in in-vitro experiments. In the brain, detached A $\beta$ monomers from aggregates by EPPS may simultaneously become subjected to multiple clearance pathways including the peripheral sink and microglial activation ${ }^{45}$. We suspect that a higher population of EPPS is required in vitro, to disaggregate pre-existing and newly forming $A \beta$ aggregates. In addition, considering that EPPS is one of the commonly used buffer substances for biological experiments, we highly recommend not using EPPS buffers for amyloid studies.

Over the last three decades, there has been an ongoing controversy of whether $A \beta$ accumulation is a cause or rather an effect of $\mathrm{AD}^{8}$. In this study, we demonstrated that $\mathrm{AD}$-related learning and memory deficits in a TG mouse model of $\mathrm{AD}$ are ameliorated by an agent capable of disaggregating $A \beta$ oligomers and fibrils. Therefore, our study supports the view that $A \beta$ aggregation is a direct driver of $\mathrm{AD}$ symptoms.

\section{Methods}

Animal studies. Ethical regulations. All animal experiments were carried out in accordance with the National Institutes of Health guide for the care and use of laboratory animals (NIH Publications No. 8023, revised 1978) and the Animal Institutional Animal Care and Use Committee of KIST (Seoul, Korea).

Preparation of memory-impaired mice by $A \beta$ aggregates and treatment of EPPS Briefly, male ICR mice (8-week-old) were purchased from Orient Bio Inc. (Seoul, Korea) and habituated for 4 days. A $\beta 42(10 \mu \mathrm{M})$ in PBS (10\% dimethyl sulfoxide (DMSO)) was incubated at $37^{\circ} \mathrm{C}$ for 1 week, to obtain various soluble oligomeric species, and then $5 \mu \mathrm{l}$ of $\mathrm{A} \beta$ or vehicle (90\% PBS and 10\% DMSO) were acutely injected into the intracerebroventricle ${ }^{47}$. A $\beta 42$ for injection was purchased from American Peptide Company. Experiments were designed in two paradigms ( $n=9-10$ per group): oral administration of EPPS (30 or $100 \mathrm{mg} \mathrm{kg}^{-1}$ per day) (1) before (pretreatment) or (2) after $A \beta$ injection (co-treatment) into mice. (1) EPPS was administered for 1 week before the $A \beta$ injection into the intracerebroventricle. EPPS was administered for another week following injection and the behavioural test (Y-maze) was performed. (2) A $\beta$ was injected on the same day when EPPS administration began for following 5 days and the behavioural test (Y-maze) was performed.

Toxicity. EPPS was orally administered to B6 mice (4-week-old, male, $n=6$ per group) as 1,000 or $2,000 \mathrm{mg} \mathrm{kg}^{-1}$ per day for 2 months, to obtain the $\mathrm{LD}_{50}$ of EPPS. During administration of EPPS, changes in mortality, body weight and hair loss of mice were observed.

Pharmacokinetics of EPPS. To evaluate pharmacokinetic profiles, EPPS was administered to SD rats via drinking water for 7 consecutive days (day 1-7) for test groups (Medicilon Preclinical Research, Shanghai LLC, Study number: 11006-14013). We measured plasma and brain concentrations of EPPS at different time points ( 24 (only for plasma), 70, 120 and 168 hours) from individual animals following oral administration (10 and $100 \mathrm{mg} \mathrm{kg}^{-1}$ per day). Eighteen SD male rats (body weight: 185.6-198.1 g) were placed under observation. The amount of drinking water that the study animals had drunk for a day ( $\sim 24$ hours) was checked and averaged at around 1,000 hours each day. Following administration of EPPS at a dose of $10 \mathrm{mg} \mathrm{kg}^{-1}$ per day, the concentrations of plasma EPPS were $2.44 \pm 0.32,7.00 \pm 2.42,3.70 \pm 0.66$ and $4.30 \pm 1.91 \mathrm{ng} \mathrm{ml}^{-1}$ at each time point $(24$ 70,120 and 168 hours). Brain EPPS concentrations were $7.52 \pm 2.85,7.03 \pm 1.83$ and $7.52 \pm 3.40 \mathrm{ng} \mathrm{ml}^{-1}$ at each time point (70,120 and 168 hours). When EPPS was administered at a dose of $100 \mathrm{mg} \mathrm{kg}^{-1}$ per day, the concentrations of plasma EPPS were $23.73 \pm 12.21,79.48 \pm 22.15,63.12 \pm 23.65$ and $33.74 \pm 5.39 \mathrm{ng} \mathrm{ml}^{-1}$ at each time point $(24,70,120$ and 168 hours) and brain EPPS were $17.86 \pm 11.88$, $9.15 \pm 2.83$ and $11.32 \pm 1.03$ at each time point (70,120 and 168 hours).

Preparation of APP/PS1 double TG mice. Double mutated TG mice were originally obtained from Jackson Laboratory (USA; strain name: B6C3-Tg (APPswe, PSEN1dE9) 85Dbo/J; stock number 004462). These APP/PS1 TG mice were maintained as double hemizygotes by crossing with WT mice on a B6C3F1 background strain.

Oral administration of EPPS to APP/PS1 double TG mice. EPPS in drinking water was freely administered to 10.5-month-old WT (male) and APP/PS1 TG 
(male) mice, with severe cognitive deficits and plaque deposits in brains, for 3.5 months with 10 or $30 \mathrm{mg} \mathrm{kg}^{-1}$ per day dosages ( $n=8-11$ per group). For control groups, water-treated TG mice (male, $n=15$ ) and age-matched WTs (male, $n=16$ ) were used. For dose-response studies, we administered EPPS $(0,0.1,1$ or $10 \mathrm{mg} \mathrm{kg}^{-1}$ per day) to 12 -month-old APP/PS1 TG mice (male) for 3 months; $0(n=8), 0.1(n=7), 1(n=8)$ or $10 \mathrm{mg} \mathrm{kg}^{-1}(n=9)$. To determine the exact dosage, all administered molecules in drinking water were set according to the average daily consumption in each cage and recalculated once a week. Animal tests were employed twice independently and all behavioural tests were performed during the light cycle.

Electrophysiology. To obtain LTP with or without EPPS administration, we prepared APP/PS1 TG $(n=4)$ and WT $(n=4)$ mice, and administered water (EPPS,$- n=2$ per group) or $30 \mathrm{mg} \mathrm{kg}^{-1}$ per day of EPPS (EPPS,$++ n=2$ per group) for 5 days in drinking water then compared LTP (BnH, Gyeonggi, Korea). To investigate CA1 circuit from transverse SC input in hippocampal slices $(400 \mu \mathrm{m}$ thick), three slices of brain section per each mouse were prepared from adult mice. Briefly, after mice were anaesthetized with isoflurane, the brain was rapidly cooled via transcardiac perfusion with ice-cold sucrose-artificial cerebrospinal fluid (CSF). The brain was removed and placed in ice-cold sucrose-artificial CSF. Coronal slices were prepared to be incubated in artificial CSF at $35^{\circ} \mathrm{C}$ for $30 \mathrm{~min}$ to recover. Slices were then incubated in artificial CSF at room temperature $\left(23-25^{\circ} \mathrm{C}\right)$ for $1-4$ hours before being placed in the recording chamber for experiments. The standard artificial CSF contained (in mM) $119 \mathrm{NaCl}, 2.5 \mathrm{KCl}, 2.5 \mathrm{CaCl}_{2}, 1.3 \mathrm{MgSO}_{4}, 1.0$ $\mathrm{NaH}_{2} \mathrm{PO}_{4}, 26.2 \mathrm{NaH}_{2} \mathrm{CO}_{3}, 11$ glucose, $1 \mathrm{Na}$ pyruvate, $0.4 \mathrm{Na}$ ascorbate saturated with $95 \% \mathrm{O}_{2}$ and $5 \% \mathrm{CO}_{2}$. Sucrose-artificial CSF contained (in $\mathrm{mM}$ ) 198 sucrose, $2.5 \mathrm{KCl}, 1 \mathrm{NaH}_{2} \mathrm{PO}_{4}, 26.2 \mathrm{NaHCO}_{3}, 11$ glucose, $1 \mathrm{Na}$ pyruvate, $0.4 \mathrm{Na}$ ascorbate saturated with $95 \% \mathrm{O}_{2}$ and $5 \% \mathrm{CO}_{2}$. All experiments were conducted at $27-29^{\circ} \mathrm{C}$. For electrophysiological experiments, electrodes with 3-6 M $\Omega$ pipette resistance were used and extracellular field recordings were obtained from the neurons under visual guidance using infrared-differential interference contrast optics guidance. CA3 and DG regions were cut away just before starting LTP experiments, to isolate CA1 lesion. Stimuli were applied to the SC pathway using a concentric bipolar electrode located $100-200 \mu \mathrm{m}$ from the recorded cell soma. Recordings were made using a multiclamp 700A (Molecular Devices, Sunnyvale, CA), digitized at $10 \mathrm{KHz}$ and filtered at $2 \mathrm{KHz}$. Input resistance and series resistance were monitored continuously during recordings. In LTP experiments, baseline EPSPs before applying pairing stimuli $(2 \mathrm{~Hz}, 2 \mathrm{~min}$ stimuli and postsynaptic depolarization to $0 \mathrm{mV}$ ) were measured for $3 \mathrm{~min}$. After pairing stimuli $(2 \mathrm{~Hz}, 2 \mathrm{~min}$ stimuli and postsynaptic depolarization to $0 \mathrm{mV}$ ), EPSPs were collected every $10 \mathrm{sec}$ for $30 \mathrm{~min}$.

Behavioural studies. Recording and analyses. Data analyses, including recordings of all behavioural responses, were transcribed manually into the computer-acceptable format by keeping research colleagues blind.

Y-maze tests. Y-maze tests are used to assess cognitive changes, short-term spatial working memory (by spontaneous alternation) and exploratory activity (by total number of arm choices) of mice placed into a black Y-maze ${ }^{16,48,49}$. The Y-maze is a three-arm horizontal maze $(40 \mathrm{~cm}$ long and $10 \mathrm{~cm}$ wide with $12-\mathrm{cm}$ high walls) in which the arms are symmetrically disposed at $120^{\circ}$ angles from each other. The task was carried out on day 1 of behavioural tests. Mice were placed at the end of one arm and allowed to move freely through the maze during an 8-min session. The number of total arm choices and sequence of arm choices were recorded. The per cent alternation is defined by proportion of arm choices that differ from the last two choices. Before each trial, the interior of the maze was sprayed with a $70 \%$ ethanol solution to erase any scent cues.

Fear-conditioning tests. Contextual and cued fear-conditioning tests measure the ability of mice to learn and remember associations between aversive experiences and environmental cues ${ }^{16,50,51}$. Hippocampal lesions interfere with contextual conditioning but not the cued, whereas amygdala lesions interfere with the conditioning of both, the context and the cue ${ }^{52,53}$. Thus, to obtain the functional recovery of the hippocampal and the amygdala lesions, both tasks (contextual and cued tasks) were carried out during days 4-7 of behavioural tests. The test was employed according to the previous methods ${ }^{16,50-54}$. On the first day of fear-conditioning tests, mice were placed into a cued box for $5 \mathrm{~min}$ to habituate and explore. The next day, for training (fear conditioning phase), mice were placed into a sound-attenuating standard operant chamber (Coulbourn, USA) for $3 \mathrm{~min}$. A 30 -sec tone $(3 \mathrm{kHz}, 85 \mathrm{~dB})$ was delivered followed by $1 \mathrm{sec}$ foot shock $(0.5 \mathrm{~mA})$. This training was repeated twice continuously within a 90 -sec interval. After 24 hours, for contextual retention tests, mice were subjected to the same chamber of conditioning and freezing response was measured for $5 \mathrm{~min}$. Responses were recorded on a video camera to score freezing, which is the lack of movement, except for respiration. Cued fear-conditioning tests were performed on the last day of the fear-conditioning study. Mice were placed into the cued box allowing exploration for $3 \mathrm{~min}$ and the conditioning tone was delivered for $1 \mathrm{~min}$ with measurement of freezing responses.

Morris water maze tests. The Morris water maze tests are used to evaluate spatial reference learning and memory of mice ${ }^{16,55,56}$. In this study, a circular water tank $\left(120 \mathrm{~cm}\right.$ diameter, $\left.25 \pm 1{ }^{\circ} \mathrm{C}\right)$ with hidden quadrants was used and the surrounding was decorated with eye-catching visual cues to orient subjected mice. A clear $12 \mathrm{~cm}$ (diameter) escape platform was placed $1.5 \mathrm{~cm}$ below the water surface, which was made opaque with white non-toxic tempera paint.
The quadrant containing the platform refers to the target zone. Hidden platform test was performed for 6 days. Mice were trained for 6 consecutive days with five trials per day as acquisition trials. Each trial began with placing the mouse into a different quadrant and allowing it to swim freely for a maximum period $(60 \mathrm{sec})$. After each mouse reached the platform (or were guided to the platform if mice were unable to locate the platform after $60 \mathrm{sec}$ ), they were returned to their home cage to dry for $20 \mathrm{~min}$. The time taken to reach the platform of each mouse refers to escape latency. On the seventh day, probe test was performed to determine memory retention without the platform for $60 \mathrm{sec}$. Each mouse was placed into the opposite quadrant of the target zone where the platform was removed (time in the target zone). Numbers of annulus crossing in probe were also calculated. Data were recorded and analysed using a video camera-based Ethovision System (Nodulus, The Netherlands).

Biochemical studies. ThS staining and histochemical analyses of $A \beta$ plaques in brain sections. After the behavioural studies, mice were deeply anaesthetized with $2 \%$ avertin $\left(20 \mathrm{\mu g} \mathrm{g}^{-1}\right.$, intraperitoneally) and perfused with $0.9 \%$ saline followed by ice-cold $4 \%$ paraformaldehyde. Excised brains were post-fixed overnight in $4 \%$ paraformaldehyde at $4{ }^{\circ} \mathrm{C}$ and immersed in $30 \%$ sucrose for 48 hours for cryoprotection. Coronal hippocampal sections $(35 \mu \mathrm{m}$; average range: bregma -1.70 to $-2.01 \mathrm{~mm}$ ) were cut (eight slices of each mouse brain) with a Cryostat (Microm HM 525, Thermo Scientific, Waltham, MA, USA) and mounted onto glass slides. A $\beta$ plaques in brains were visualized using ThS staining. ThS was dissolved in $50 \%$ of ethanol at $500 \mu \mathrm{M}$ and brain sections were stained for $7 \mathrm{~min}$ As a differentiation step to remove a nonspecific binding of the dye, a slide was soaked into 100, 95 and $90 \%$ ethanol solutions for 10 sec each and then moved into PBS. A $\beta$ plaques, GABA and inflammation-related proteins such as GFAP or Iba-1 were stained with primary antibodies with fluorescence-labelling secondary antibodies. Detailed information about the antibodies is included in the Supplementary Information. The images of plaques were taken on an Olympus fluorescent microscope using fluorescent filter sets ${ }^{57}$. Numbers and area of plaques were obtained by Image-J programme (NIH). Analyses of plaque distributions were transcribed manually into the computer-acceptable format by keeping research colleagues blind.

Blotting analyses and quantification of $A \beta$-soluble fraction of brain lysates. Mice were killed and hippocampal and cortical regions of mouse brains were dissected separately. Brain tissues were homogenized in ice-cold lysis buffer $(10 \mathrm{mM}$ Tris-HCl, $5 \mathrm{mM}$ EDTA in $320 \mathrm{mM}$ sucrose $\mathrm{pH}$ 7.4) containing $1 \times$ proteinase inhibitor cocktail ${ }^{58}$. Homogenized tissue was incubated in ice for $20 \mathrm{~min}$ and centrifuged at 14,000 r.p.m., $4^{\circ} \mathrm{C}$ for $30 \mathrm{~min}$. The supernatant (soluble fraction) of brain lysates was used in A $\beta 42$ ELISA, western blots and dot blots for biochemical changes and soluble $A \beta$ analyses, respectively. Concentrations of soluble fractions of brain lysates were determined by Bradford protein assay. Protein samples $(20 \mu \mathrm{g})$ were loaded on each lane of SDS-PAGE gels for western blot analyses and used for $A \beta 42$ sandwich ELISA (A $\beta 42$ sandwich ELISA kit from Invitrogen). Measurements of $A \beta 42$ in soluble fractions were performed according to the manufacturer's instructions, with fivefold diluted soluble fraction samples. Protein samples in soluble fraction of brain lysates, 20 and $1 \mu \mathrm{g}$, were spotted for the dot blot analysis to detect oligomers and A $\beta$, respectively. Total-CREB, p-CREB, Iba- 1 total-JNK, $p$-JNK, GFAP, APP, A $\beta$ (6E10), protein oligomers (A11) and $\beta$-actin (a loading control) were measured. The detail information of antibodies is included in Supplementary Information.

Quantification of $A \beta$-insoluble fraction of brain lysates. To obtain $A \beta$-insoluble fraction in brain lysates, a guanidine buffer $(5 \mathrm{mM}$ guanidine- $\mathrm{HCl}, 50 \mathrm{mM}$ Tris- $\mathrm{HCl} \mathrm{pH} \mathrm{8.0)} \mathrm{containing} 1 \times$ proteinase inhibitor cocktail was added to the pellet of brain lysates and the mixtures were incubated at room temperature for 3 hours with shaking to dissolve $\mathrm{A} \beta$-insoluble fraction. After centrifugation at $4{ }^{\circ} \mathrm{C}$ for 2 hours, levels of dissolved $A \beta$ in supernatant (insoluble fraction) were measured by A $\beta 42$ sandwich ELISA kit purchased from Invitrogen (KHB3442). Protein concentrations of insoluble fractions were determined by Bradford protein assay and $10 \mu \mathrm{g}$ of protein samples were used. Measurements were performed according to the manufacturer's instructions.

In vitro studies. Preparation of $A \beta$ aggregates. In-house synthetic $A \beta$ peptides were dissolved in DMSO to prepare $A \beta 40(50 \mathrm{mM})$ and $A \beta 42(25 \mathrm{mM})$ stocks ${ }^{13,59}$. Each stock was then diluted with deionized water to make $A \beta$ solutions, $A \beta 40$ $(500 \mu \mathrm{M})$ and $\mathrm{A} \beta 42(250 \mu \mathrm{M})$. A $\beta$ solutions were incubated for $5-10$ days at $37^{\circ} \mathrm{C}$ to obtain $A \beta$ oligomers and fibrils.

$A \beta$ disaggregation assays. Preformed $A \beta$ aggregates were diluted with deionized water or EPPS solution $(20 \mathrm{mM})$ and incubated for 1,2,3 and 7 days; final concentration of $A \beta 40$ was $50 \mu \mathrm{M}$ and that of $A \beta 42$ was $25 \mu \mathrm{M}$. A $\beta$ fibril formation was monitored using the ThT assay and transmission electron microscopy image analyses (Philips CM-30 transmission electron microscope) ${ }^{60}$. For ThT assay, preformed $A \beta$ aggregates were incubated in $200,20,2,0.2,0.02,0.002,0.0002$ or $0 \mathrm{mM}$ of EPPS at $37^{\circ} \mathrm{C}$ for 3 days. Fluorescence of $\mathrm{A} \beta$-bound ThT was measured at $450 \mathrm{~nm}(\mathrm{ex})$ and $485 \mathrm{~nm}(\mathrm{em})$ using an EnSpire plate reader (Perkin-Elmer) ${ }^{26,61}$ To analyse size distribution of $A \beta$ species after incubation, we employed SDSPAGE and PICUP chemistry ${ }^{29}$. Briefly, A $\beta$ samples were irradiated two times (each for $1 \mathrm{sec})$ to cross-link peptides with $\mathrm{Ru}(\mathrm{Bpy})\left(\mathrm{Cl}_{2}\right)$ and ammonium persulfate. Cross-linked $A \beta$ samples were analysed on 1.0-mm-thick $10-20 \%$ gradient 
tris-tricine gels. After separation, gels were stained using silver-staining kit to visualize peptide bands. To confirm the cytotoxicity of A $\beta$ aggregates, MTT (3-(4,5-dimethylthiazol-2-yl)-2,5-diphenyltetrazolium bromide) assays were performed according to the method described previously using HT-22 neuronal cell line (murine brain hippocampal cells) ${ }^{13}$. First, $A \beta 42$ or $A \beta 40$ was incubated for several days in $37^{\circ} \mathrm{C}$ to obtain $A \beta$ aggregates. Second, the aggregates were incubated for 7 days $(A \beta(7 d))$ with or without EPPS. Finally, HT-22 cells were seeded and were exposed to the $A \beta$ aggregates or $A \beta(7 d)$ for 24 hours. Final concentration of $A \beta 40$ and $A \beta 42$ for treatments was 2.5 and $5 \mu \mathrm{M}$ with or without $2 \mathrm{mM}$ EPPS in DMEM (0.05\% DMSO). The MTT reagent and the stop solution were then added and absorbance was read via an EnSpire plate reader (Perkin-Elmer)

Size exclusion chromatography. SEC experiments were performed to confirm the disaggregated $A \beta$ via EPPS ${ }^{62}$. We set the analysis system at $25^{\circ} \mathrm{C}$ using a SEC-300 (Acclaim SEC-300, $5 \mu \mathrm{m}, 4.6 \times 300 \mathrm{~mm}$, Thermo Scientific) column on an Ultimate 3000 UHPCL (Thermo Scientific). PBS was prepared as a mobile phase and the flow rate was set at $0.35 \mathrm{ml} \mathrm{min}^{-1}$. Ten microlitres of prepared $A \beta 42$ samples and size controls (60 kDa BSA, $14 \mathrm{kDa}$ thioredoxin and $\mathrm{A} \beta 42$ monomer) were injected and detected by ultraviolet absorbance at $280 \mathrm{~nm}$.

Surface plasmon resonance analysis. The surface plasmon resonance analysis was performed using CM5 sensor chips and Biacore T200 instrument (GE Healthcare $)^{30,63}$. Briefly, PBS-P $(10 \mathrm{mM}$ phosphate, $135 \mathrm{mM} \mathrm{NaCl}, 27 \mathrm{mM} \mathrm{KCl}$ and $0.05 \%$ SP20) was used as a buffer at $25^{\circ} \mathrm{C}$. A $\beta 40$ was dissolved in DMSO to make $5 \mathrm{mM}$ stock. The stock was tenfold diluted by deionized water and incubated at $37^{\circ} \mathrm{C}$ for $5-7$ days until the formation of oligomers, which was confirmed by SDS-PAGE with cross-link. Prepared A $\beta 40$ oligomers were diluted with $10 \mathrm{mM}$ sodium acetate solution ( $\mathrm{pH} 4.0$ ) to make $40 \mu \mathrm{g} \mathrm{ml}^{-1}$ of $\mathrm{A} \beta 40$ and immobilized to the sensor chip surface by amine coupling chemistry. The remaining activated surface groups were blocked with $1 \mathrm{M}$ ethanolamine ( $\mathrm{pH} 8.0$ ); immobilization value was 9,000 RU and theoretical $R_{\max }$ was $525 \mathrm{RU}$. EPPS was prepared in the same buffer as serial-diluted samples: $0.075,0.15,0.3,0.6,1.2,2.4,4.8,9.6$ and $19.2 \mathrm{mM}$. Bimolecular interaction was measured by the binding response when EPPS was injected.

Statistical analyses. Graphs were obtained with GraphPad Prism 5 and statistical analyses were performed with Student's paired $t$-tests, unpaired $t$-tests, repeatedmeasures analysis of variance or one-way analysis of variance followed by Bonferroni's post-hoc comparisons $\left({ }^{*} P<0.05,{ }^{* *} P<0.01,{ }^{* * *} P<0.001,{ }^{\#} P<0.05\right.$, ${ }^{\# \#} P<0.01,{ }^{\# \#} P<0.001$; other comparisons were not significant). The error bars represent the s.e.m.

\section{References}

1. Bateman, R. J. et al. Clinical and biomarker changes in dominantly inherited Alzheimer's disease. N. Engl. J. Med. 367, 795-804 (2012).

2. Dineley, K. T. et al. Amyloid-beta oligomers impair fear conditioned memory in a calcineurin-dependent fashion in mice. J. Neurosci. Res. 88, 2923-2932 (2010).

3. Haass, C. \& Selkoe, D. J. Soluble protein oligomers in neurodegeneration: lessons from the Alzheimer's amyloid beta-peptide. Nat. Rev. Mol. Cell Biol. 8, 101-112 (2007).

4. Salomone, S., Caraci, F., Leggio, G. M., Fedotova, J. \& Drago, F. New pharmacological strategies for treatment of Alzheimer's disease: focus on disease modifying drugs. Br. J. Clin. Pharmacol. 73, 504-517 (2012).

5. Gervais, F. et al. Targeting soluble Abeta peptide with Tramiprosate for the treatment of brain amyloidosis. Neurobiol. Aging 28, 537-547 (2007).

6. McLaurin, J. et al. Cyclohexanehexol inhibitors of Abeta aggregation prevent and reverse Alzheimer phenotype in a mouse model. Nat. Med. 12, 801-808 (2006).

7. Yang, F. et al. Curcumin inhibits formation of amyloid beta oligomers and fibrils, binds plaques, and reduces amyloid in vivo. J. Biol. Chem. 280, 5892-5901 (2005)

8. Selkoe, D. J. Preventing Alzheimer's disease. Science 337, 1488-1492 (2012).

9. Selkoe, D. J. Resolving controversies on the path to Alzheimer's therapeutics. Nat. Med. 17, 1060-1065 (2011).

10. Jack, Jr C. R. et al. Hypothetical model of dynamic biomarkers of the Alzheimer's pathological cascade. Lancet Neurol. 9, 119-128 (2010).

11. Green, R. C. et al. Effect of tarenflurbil on cognitive decline and activities of daily living in patients with mild Alzheimer disease: a randomized controlled trial. JAMA 302, 2557-2564 (2009).

12. Karran, E., Mercken, M. \& De Strooper, B. The amyloid cascade hypothesis for Alzheimer's disease: an appraisal for the development of therapeutics. Nat. Rev. Drug Discov. 10, 698-712 (2011).

13. Kim, H. Y., Kim, Y., Han, G. \& Kim, D. J. Regulation of in vitro Abeta1-40 aggregation mediated by small molecules. J. Alzheimers Dis. 22, 73-85 (2010).

14. Van Dam, D. \& De Deyn, P. P. Animal models in the drug discovery pipeline for Alzheimer's disease. Br. J. Pharmacol. 164, 1285-1300 (2011).

15. Cao, D., Lu, H., Lewis, T. L. \& Li, L. Intake of sucrose-sweetened water induces insulin resistance and exacerbates memory deficits and amyloidosis in a transgenic mouse model of Alzheimer disease. J. Biol. Chem. 282, 36275-36282 (2007).

16. Bryan, K. J., Lee, H., Perry, G., Smith, M. A. \& Casadesus, G. in Methods of Behavior Analysis in Neuroscience. (eds Buccafusco, J. J.2nd edn, 2009).

17. Yan, P. et al. Matrix metalloproteinase-9 degrades amyloid-beta fibrils in vitro and compact plaques in situ. J. Biol. Chem. 281, 24566-24574 (2006).

18. Price, J. L. \& Morris, J. C. Tangles and plaques in nondemented aging and 'preclinical' Alzheimer's disease. Ann. Neurol. 45, 358-368 (1999).

19. Morris, J. C. et al. Cerebral amyloid deposition and diffuse plaques in 'normal' aging: evidence for presymptomatic and very mild Alzheimer's disease. Neurology 46, 707-719 (1996).

20. Sarsoza, F. et al. A fibril-specific, conformation-dependent antibody recognizes a subset of Abeta plaques in Alzheimer disease, Down syndrome and Tg2576 transgenic mouse brain. Acta Neuropathol. 118, 505-517 (2009).

21. Vina, J. \& Lloret, A. Why women have more Alzheimer's disease than men: gender and mitochondrial toxicity of amyloid-beta peptide. J. Alzheimers Dis. 20(Suppl 2): S527-S533 (2010).

22. Ott, B. R., Lapane, K. L. \& Gambassi, G. Gender differences in the treatment of behavior problems in Alzheimer's disease. SAGE Study Group. Systemic Assessment of Geriatric drug use via Epidemiology. Neurology 54, 427-432 (2000).

23. Heneka, M. T. Inflammation in Alzheimer's disease. Clin. Neurosci. Res. 6, 247-260 (2006).

24. Scott Bitner, R. Cyclic AMP response element-binding protein (CREB) phosphorylation: a mechanistic marker in the development of memory enhancing Alzheimer's disease therapeutics. Biochem. Pharmacol. 83, 705-714 (2012).

25. Jo, S. et al. GABA from reactive astrocytes impairs memory in mouse models of Alzheimer's disease. Nat. Med. 20, 886-896 (2014).

26. Noormagi, A., Primar, K., Tougu, V. \& Palumaa, P. Interference of low-molecular substances with the thioflavin-T fluorescence assay of amyloid fibrils. J. Pept. Sci. 18, 59-64 (2012).

27. Shankar, G. M. et al. Amyloid-beta protein dimers isolated directly from Alzheimer's brains impair synaptic plasticity and memory. Nat. Med. 14, 837-842 (2008).

28. Cleary, J. P. et al. Natural oligomers of the amyloid-beta protein specifically disrupt cognitive function. Nat. Neurosci. 8, 79-84 (2005).

29. Bitan, G. \& Teplow, D. B. Rapid photochemical cross-linking--a new tool for studies of metastable, amyloidogenic protein assemblies. Acc. Chem. Res. 37, 357-364 (2004).

30. Richter, L. et al. Amyloid beta 42 peptide (Abeta42)-lowering compounds directly bind to Abeta and interfere with amyloid precursor protein (APP) transmembrane dimerization. Proc. Natl Acad. Sci. USA 107, 14597-14602 (2010).

31. O'Hare, E. et al. Orally bioavailable small molecule drug protects memory in Alzheimer's disease models. Neurobiol. Aging 34, 1116-1125 (2013).

32. Goverdhan, P., Sravanthi, A. \& Mamatha, T. Neuroprotective effects of meloxicam and selegiline in scopolamine-induced cognitive impairment and oxidative stress. Int. J. Alzheimers Dis. 2012, 974013 (2012).

33. Sinha, S. et al. Lysine-specific molecular tweezers are broad-spectrum inhibitors of assembly and toxicity of amyloid proteins. J. Am. Chem. Soc. 133, 16958-16969 (2011).

34. Legleiter, J. et al. Effect of different anti-Abeta antibodies on Abeta fibrillogenesis as assessed by atomic force microscopy. J. Mol. Biol. 335, 997-1006 (2004).

35. Frenkel, D., Katz, O. \& Solomon, B. Immunization against Alzheimer's beta -amyloid plaques via EFRH phage administration. Proc. Natl Acad. Sci. USA 97, 11455-11459 (2000).

36. Puzzo, D. et al. Endogenous amyloid-beta is necessary for hippocampal synaptic plasticity and memory. Ann. Neurol. 69, 819-830 (2011).

37. Parihar, M. S. \& Brewer, G. J. Amyloid-beta as a modulator of synaptic plasticity. J. Alzheimers Dis. 22, 741-763 (2010).

38. Morley, J. E. et al. A physiological role for amyloid-beta protein:enhancement of learning and memory. J. Alzheimers Dis. 19, 441-449 (2010).

39. Garcia-Osta, A. \& Alberini, C. M. Amyloid beta mediates memory formation. Learn. Mem. 16, 267-272 (2009).

40. Grant, J. L. et al. Reversal of paralysis and reduced inflammation from peripheral administration of beta-amyloid in TH1 and TH17 versions of experimental autoimmune encephalomyelitis. Sci. Transl. Med. 4, 145ra105 (2012).

41. Fraser, P. E., Nguyen, J. T., Chin, D. T. \& Kirschner, D. A. Effects of sulfate ions on Alzheimer beta/A4 peptide assemblies: implications for amyloid fibril-proteoglycan interactions. J. Neurochem. 59, 1531-1540 (1992).

42. Ferrao-Gonzales, A. D. et al. Controlling \{beta\}-amyloid oligomerization by the use of naphthalene sulfonates: trapping low molecular weight oligomeric species. J. Biol. Chem. 280, 34747-34754 (2005).

43. Gauthier, S. et al. Effect of tramiprosate in patients with mild-to-moderate Alzheimer's disease: exploratory analyses of the MRI sub-group of the Alphase study. J. Nutr. Health Aging 13, 550-557 (2009). 
44. Santa-Maria, I., Hernandez, F., Moreno, F. J. \& Avila, J. Taurine, an inducer for tau polymerization and a weak inhibitor for amyloid-beta-peptide aggregation. Neurosci. Lett. 429, 91-94 (2007).

45. Citron, M. Alzheimer's disease: strategies for disease modification. Nat. Rev. Drug Discov. 9, 387-398 (2010).

46. Paxinos, G. \& Franklin, B. J. The Mouse Brain in Stereotaxic Coordinates 2nd edn (Academic Press, 2001).

47. Kim, H. V. et al. Amelioration of Alzheimer's disease by neuroprotective effect of sulforaphane in animal model. Amyloid 20, 7-12 (2013).

48. Meunier, J., Ieni, J. \& Maurice, T. The anti-amnesic and neuroprotective effects of donepezil against amyloid beta25-35 peptide-induced toxicity in mice involve an interaction with the sigmal receptor. Br. J. Pharmacol. 149, 998-1012 (2006).

49. Tsunekawa, H., Noda, Y., Mouri, A., Yoneda, F. \& Nabeshima, T. Synergistic effects of selegiline and donepezil on cognitive impairment induced by amyloid beta (25-35). Behav. Brain Res. 190 , 224-232 (2008).

50. Fanselow, M. S. \& Tighe, T. J. Contextual conditioning with massed versus distributed unconditional stimuli in the absence of explicit conditional stimuli. J. Exp. Psychol. Anim. Behav. Process. 14, 187-199 (1988).

51. LeDoux, J. E. Emotion: clues from the brain. Annu. Rev. Psychol. 46, 209-235 (1995).

52. Phillips, R. G. \& LeDoux, J. E. Differential contribution of amygdala and hippocampus to cued and contextual fear conditioning. Behav. Neurosci. 106, 274-285 (1992).

53. Curzon, P., Rustay, N. R. \& Browman, K. E. in Methods of Behavior Analysis in Neuroscience 2nd edn (eds Buccafusco, J. J.) 2.19-2.37 (CRC Press, Boca Ranton, Florida, USA, 2009).

54. Wang, D. et al. The allosteric potentiation of nicotinic acetylcholine receptors by galantamine ameliorates the cognitive dysfunction in beta amyloid25-35 i.c.v.-injected mice: involvement of dopaminergic systems. Neuropsychopharmacology 32, 1261-1271 (2007).

55. Morris, R. G., Garrud, P., Rawlins, J. N. \& O’Keefe, J. Place navigation impaired in rats with hippocampal lesions. Nature 297, 681-683 (1982).

56. D'Hooge, R. \& De Deyn, P. P. Applications of the Morris water maze in the study of learning and memory. Brain Res. Rev. 36, 60-90 (2001).

57. Li, Z., Herrmann, K. \& Pohlenz, F. Lateral scanning confocal microscopy for the determination of in-plane displacements of microelectromechanical systems devices. Opt. Lett. 32, 1743-1745 (2007).

58. Dunah, A. W. et al. Sp1 and TAFII130 transcriptional activity disrupted in early Huntington's disease. Science 296, 2238-2243 (2002).

59. Kim, Y. S., Moss, J. A. \& Janda, K. D. Biological tuning of synthetic tactics in solid-phase synthesis: application to A beta(1-42). J. Org. Chem. 69, 7776-7778 (2004).

60. Kline, T. et al. Potent, novel in vitro inhibitors of the Pseudomonas aeruginosa deacetylase LpxC. J. Med. Chem. 45, 3112-3129 (2002).
61. LeVine, 3rd H. Thioflavine T interaction with synthetic Alzheimer's disease beta-amyloid peptides: detection of amyloid aggregation in solution. Protein Sci. 2, 404-410 (1993).

62. Nicoll, A. J. et al. Amyloid-beta nanotubes are associated with prion protein-dependent synaptotoxicity. Nat. Commun. 4, 2416 (2013).

63. Cannon, M. J., Williams, A. D., Wetzel, R. \& Myszka, D. G. Kinetic analysis of beta-amyloid fibril elongation. Anal. Biochem. 328, 67-75 (2004).

\section{Acknowledgements}

This work was supported by Korea Institute of Science and Technology Institutional Programs (KIST 2E25023 and 2E24582) and KHIDI (HI14C0466). We thank Dr Jeiwon Cho (KIST) for behaviour test instruments, Dr Jun-Seok Lee (KIST) for Y-maze analysis programmes and GE Healthcare Korea/Japan for Biacore analyses. We thank Dr Eun-Mi Hur (KIST), Dr Dennis W. Choi (Stony Brook University), Rafa Tasneem (Wellesley University) and Dr Bruce Hirayama (UCLA) for editing advices. LTP studies were performed at $\mathrm{BnH}$. The cover art was created and donated by Ms Na Yun Kim.

\section{Author contributions}

H.Y K., H.V.K., S.J., S.Y.C., C.J.L., D.J.K. and Y.K. designed experiments. H.Y.K. made a major contribution in all the experiments. Y.K. synthesized peptides. H.V.K. made infusion mice and performed all the behavioural tests. H.Y.K., S.J. and H.V.K. performed brain tissue analyses. H.Y.K., H.V.K. and S.Y.C. performed Morris water maze test and maintained the environment for animals, and analysed genotypes and $A \beta$ plaques quantification. H.Y.K. performed all of the in vitro assays. H.Y.K., H.V.K., C.J.L. and Y.K. wrote the manuscript. Y.K. supervised all experiments and analyses.

\section{Additional information}

Supplementary Information accompanies this paper at http://www.nature.com/ naturecommunications

Competing financial interests: The authors declare no competing financial interests.

Reprints and permission information is available online at http://npg.nature.com/ reprintsandpermissions/

How to cite this article: Kim, H. Y. et al. EPPS rescues hippocampus-dependent cognitive deficits in APP/PS1 mice by disaggregation of amyloid- $\beta$ oligomers and plaques. Nat. Commun. 6:8997 doi: 10.1038/ncomms9997 (2015).

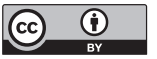

This work is licensed under a Creative Commons Attribution 4.0 International License. The images or other third party material in this article are included in the article's Creative Commons license, unless indicated otherwise in the credit line; if the material is not included under the Creative Commons license, users will need to obtain permission from the license holder to reproduce the material. To view a copy of this license, visit http://creativecommons.org/licenses/by/4.0/ 


\section{Corrigendum: EPPS rescues hippocampus- dependent cognitive deficits in APP/PS1 mice by disaggregation of amyloid- $\beta$ oligomers and plaques}

Hye Yun Kim, Hyunjin Vincent Kim, Seonmi Jo, C. Justin Lee, Seon Young Choi, Dong Jin Kim \& YoungSoo Kim

Nature Communications 6:8997 doi: 10.1038/ncomms9997 (2015); Published 8 Dec 2015; Updated 15 Feb 2016

This Article contains errors in Figs 3 and 4. In Fig. 3h, the $x$ axis should have been labelled 'TG', and in Fig. 4a, labels denoting the EPPS dose for each image were inadvertently removed. The correct versions of these two figures follow.
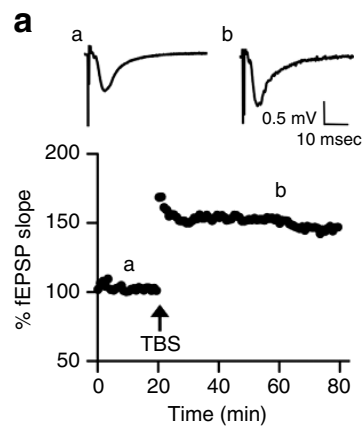

e

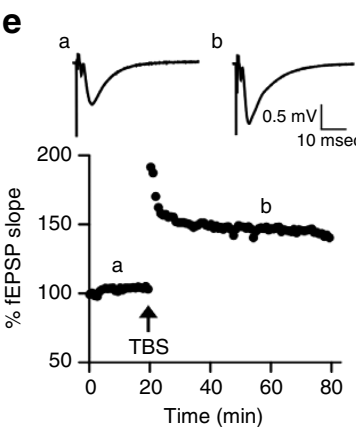

b

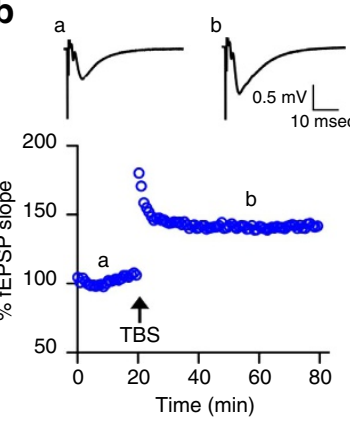

f<smiles>C1CCCCC1</smiles><smiles>CCCC</smiles>

$\mathrm{b}$
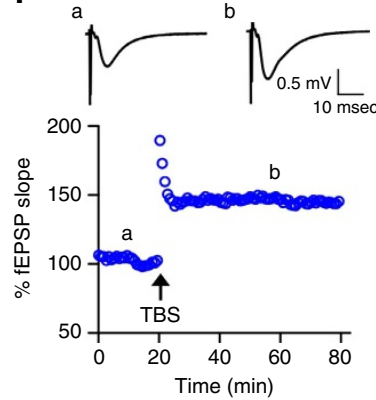

C

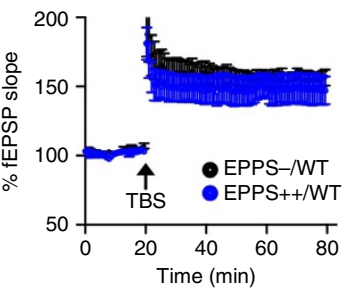

g

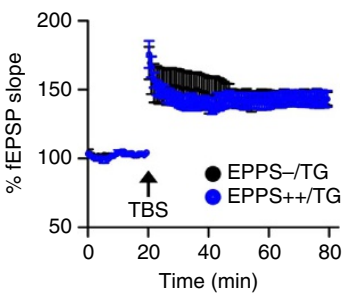

d

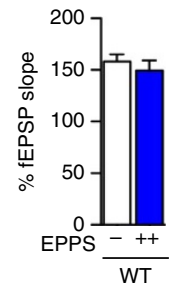

h

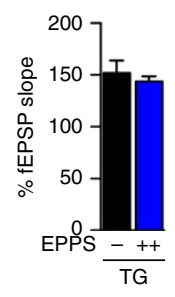

Figure 3 | 
a

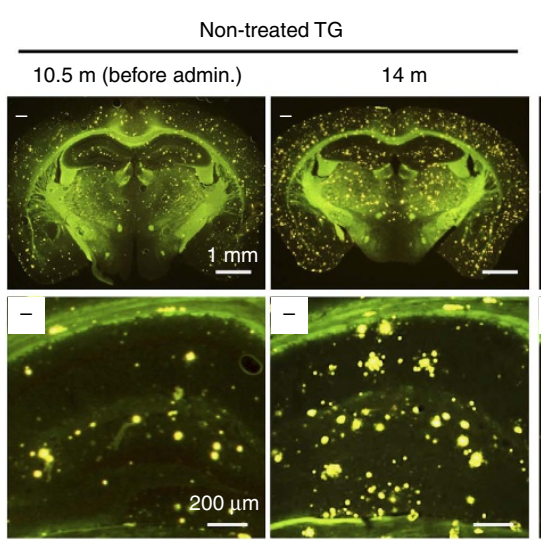

b

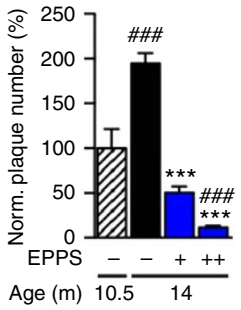

C

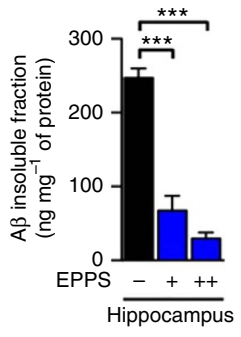

d
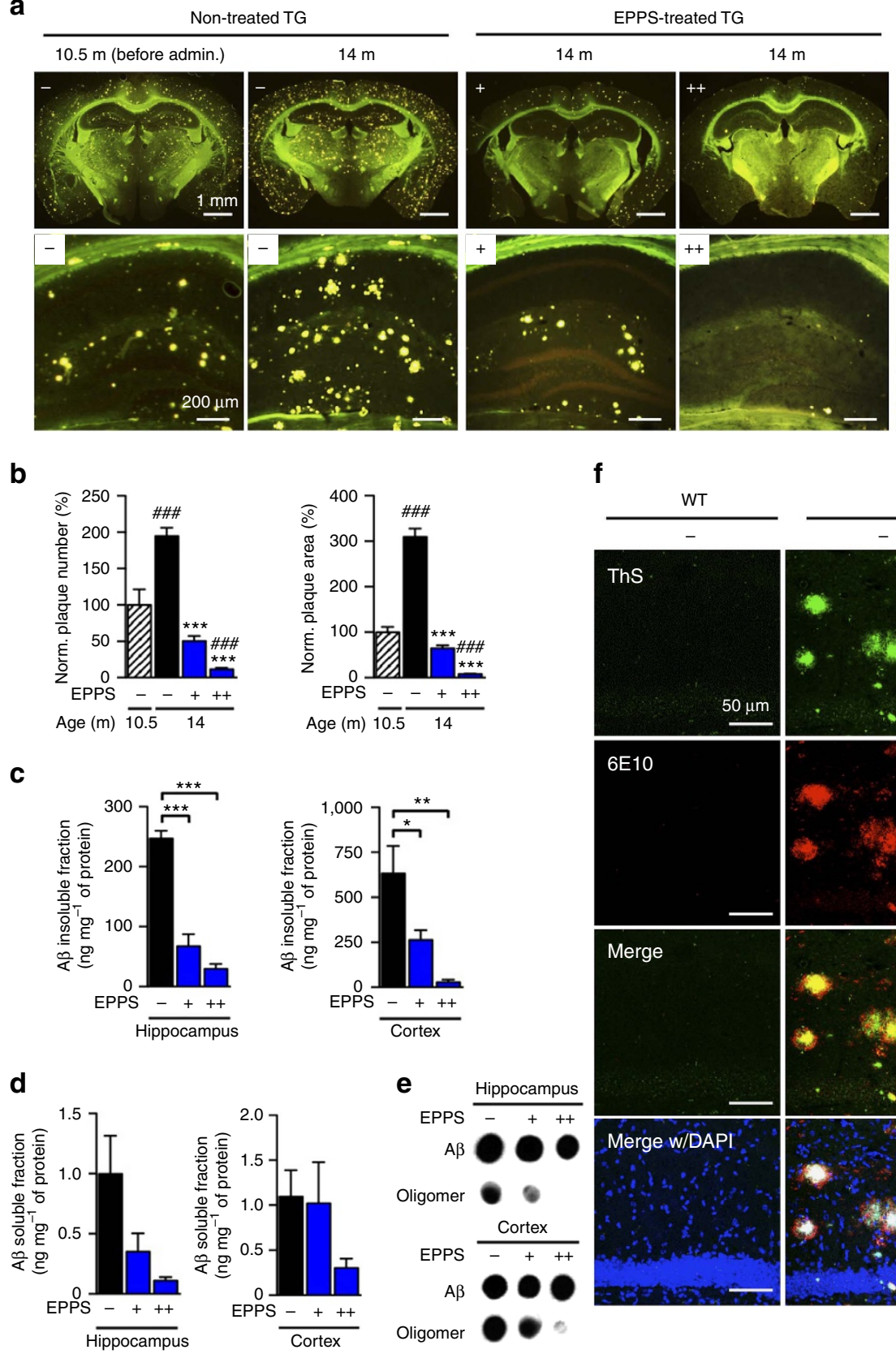

f
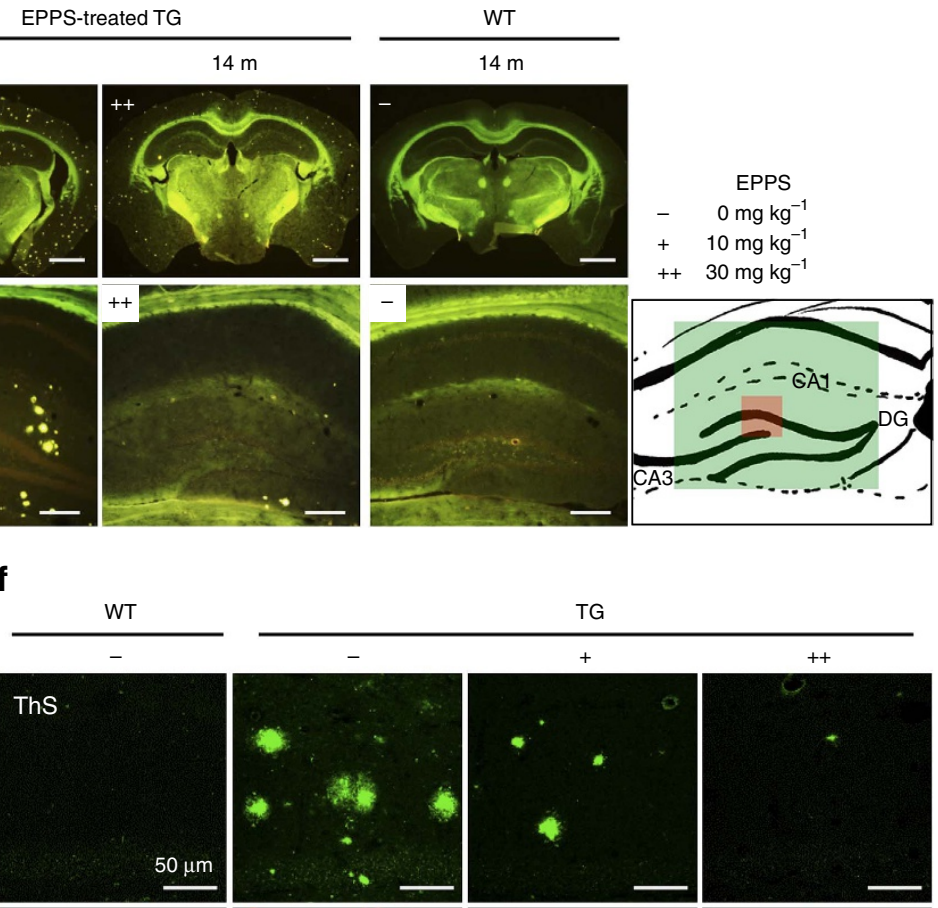

E10
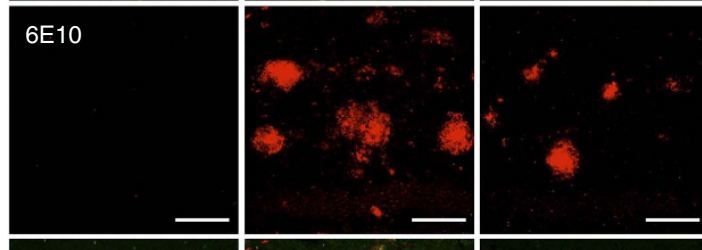

Merge
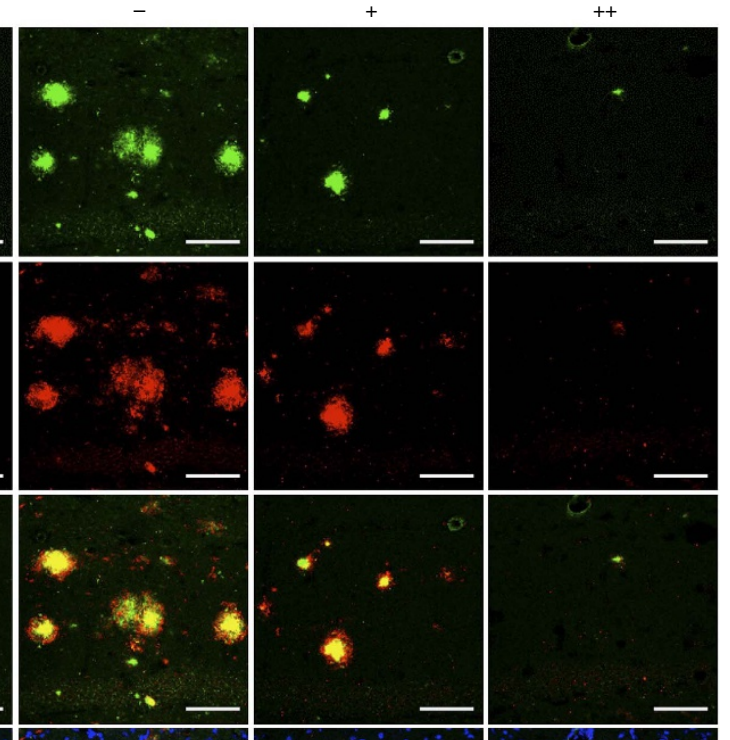

e $\operatorname{EPPS} \frac{\text { Hippocampus }}{-++++}$ Oligome $\mathrm{A} \beta$

EPPS

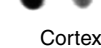

$A \beta$

Oligomer

g

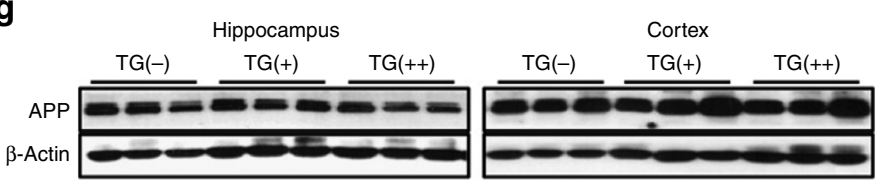

Figure 4 l

cc) This work is licensed under a Creative Commons Attribution 4.0 International License. The images or other third party material in this article are included in the article's Creative Commons license, unless indicated otherwise in the credit line; if the material is not included under the Creative Commons license, users will need to obtain permission from the license holder to reproduce the material. To view a copy of this license, visit http://creativecommons.org/licenses/by/4.0/ 